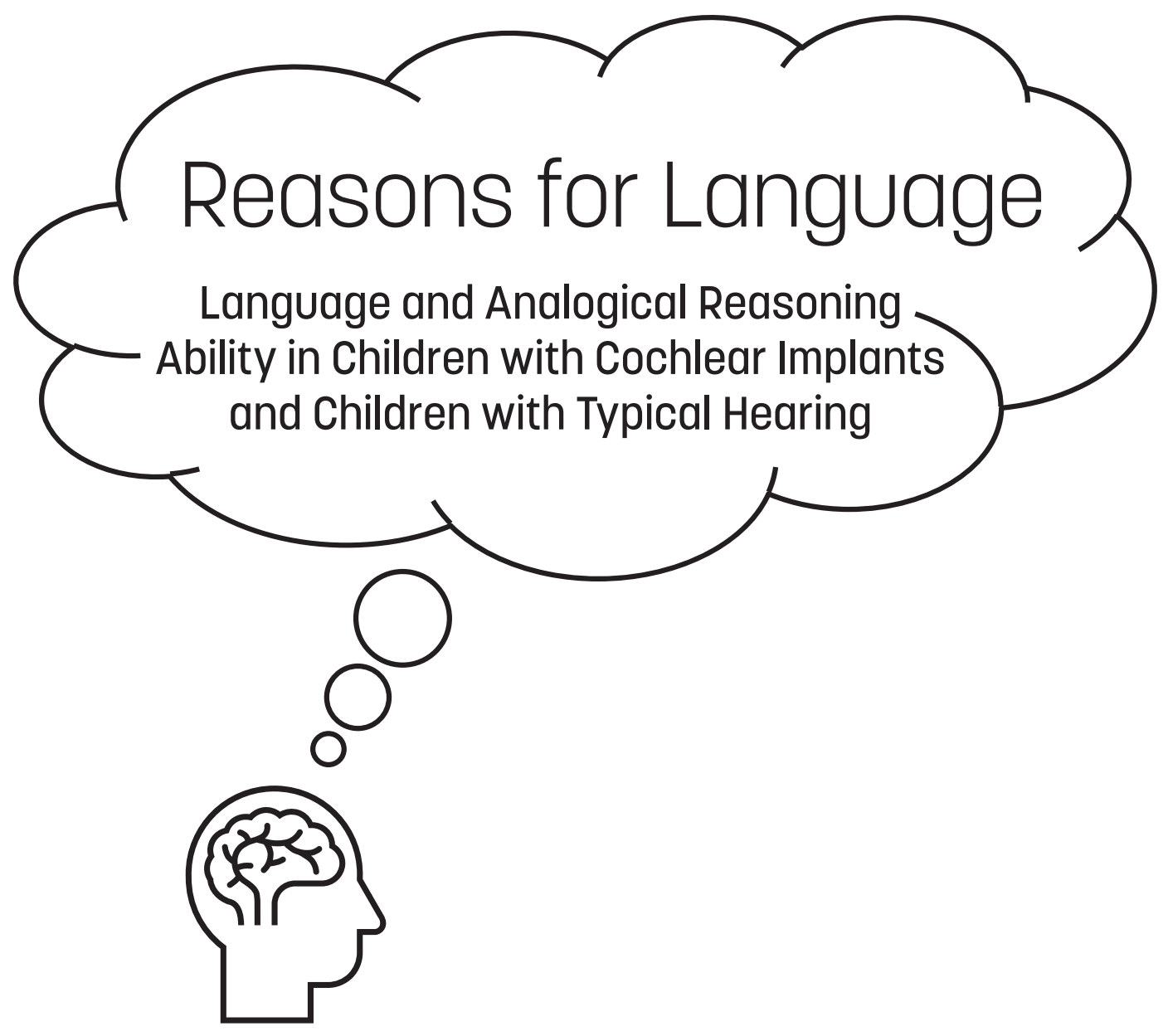

Michaela Socher 


\title{
Reasons for Language \\ Language and Analogical Reasoning Ability in Children with Cochlear Implants and Children with Typical Hearing
}

\author{
Michaela Socher
}

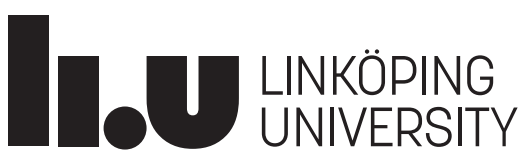

Linköping University

Department of Behavioural Sciences and Learning

Disability Research Division

SE-581 83 Linköping, Sweden

Linköping 2020 
Linköping Studies in Arts and Science • No. 795

Studies from the Swedish Institute for Disability Research • No. 101

At the Faculty of Arts and Sciences at Linköping University, research and doctoral studies are carried out within broad problem areas. Research is organized in interdisciplinary research environments and doctoral studies mainly in graduate schools. Jointly, they publish the series Linköping Studies in Arts and Sciences. This thesis comes from Disability Research Division at the Department of Behavioural Sciences and Learning.

Distributed by:

Department of Behavioural Science and Learning

Linköping University

SE-581 83 Linköping

Michaela Socher

Reasons for Language

Language and Analogical Reasoning Ability in Children with

Cochlear Implants and Children with Typical Hearing

Edition 1:1

ISBN 978-91-7929-791-6

ISSN 0282-9800

ISSN 1650-1128

(C) Michaela Socher, 2020

Published articles have been reprinted with permission from the respective copyright holder.

Typeset using $\mathrm{X}_{\mathrm{H}} \mathrm{T}_{\mathrm{E}} \mathrm{X}$

Printed by LiU-Tryck, Linköping 2020 


\begin{abstract}
The usage-based model of language acquisition assumes that language is learned by its usage. General cognitive processes, especially analogical reasoning ability, are assumed to lead to the understanding of words and grammatical structures. It has been argued that the time of language or auditory deprivation children with cochlear implants (CIs) often experience early in life, might affect both their language and their cognitive abilities. Children with CIs have disadvantages in terms of language acquisition as they start receiving language input later than peers with typical hearing $(\mathrm{TH})$, and the perceptual quality of the input is reduced. However, they might have additional difficulties in language acquisition if their analogical reasoning ability is negatively influenced by the language or auditory deprivation early in life. The results found in this thesis show that the language delays often seen in children with CIs are not explained by differences in analogical reasoning ability. Results indicate that analogical reasoning ability has a limited influence on language acquisition for the tested age-group. However, language abilities affect the performance on analogical reasoning tasks which are either verbal or can be supported by verbal strategies. This needs to be taken into consideration when comparing analogical reasoning ability of children with CIs and children with TH. In addition, the results from this thesis indicate that the structure of the mental lexicon is associated with the communication skills of children with CIs. The structure of the mental lexicon is most likely influenced by the amount of language input a child receives. The main implication of the results is that emphasis should be put on reducing the duration of language deprivation and to improve the quality of the language input for children with CIs.
\end{abstract}




\section{Contents}

Abstract iii

Contents iv

List of Figures v v v

List of Tables vi v vi v v

List of Papers 1

1 Introduction 3

1.1 Analogical Reasoning . . . . . . . . . . . . . . . . . . 5

1.2 Language and Analogical Reasoning . . . . . . . . . . . . . 7

1.3 Children with Cochlear Implants . . . . . . . . . . . . . . . . . 10

1.4 Summary . . . . . . . . . . . . . . . . . . . . . . . . . . . . . 16

1.5 General Aims and Study Rationale . . . . . . . . . . . . . . 17

2 Empirical Studies 19

2.1 General Method . . . . . . . . . . . . . . . . . . . . . . . . . . . . . . . .

2.2 Methodological Challenges . . . . . . . . . . . . . . . . 30

2.3 Summary of the papers . . . . . . . . . . . . . . . 32

\begin{tabular}{ll|l}
3 & Discussion & 37
\end{tabular}

3.1 Summary of the results . . . . . . . . . . . . 37

3.2 Language and Analogical Reasoning: A reciprocal relationship? 38

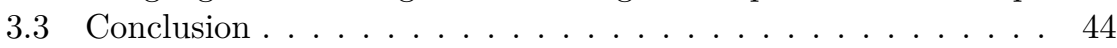

3.4 Future Directions . . . . . . . . . . . . . . . . . 45

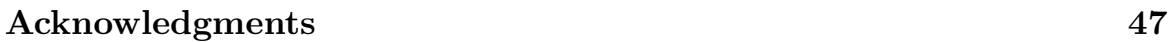

Bibliography 


\section{List of Figures}

$1 \quad$ Verbal and non-verbal analogical reasoning . . . . . . . . . . . . 5

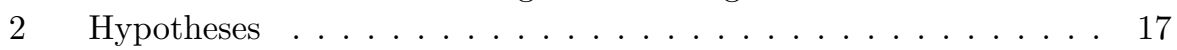

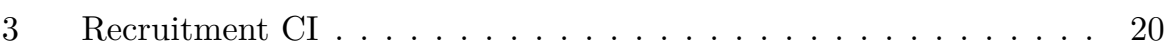

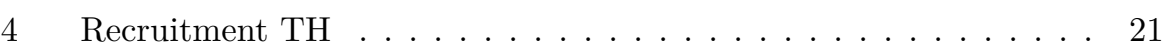

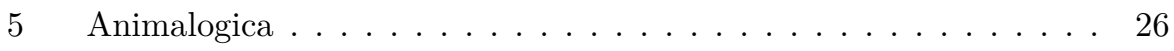

$6 \quad$ Cognitive Training . . . . . . . . . . . . . . . . 30

$7 \quad$ Thesis results $\ldots \ldots \ldots \ldots \ldots \ldots \ldots$ 


\section{List of Tables}

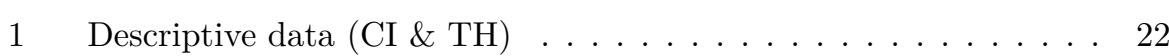

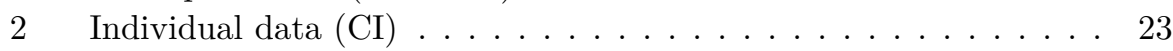

3 Cognitive tests and Language tests . . . . . . . . . . . . . . . . 24 


\section{List of Papers}

This thesis is based on the following papers, referred to in the text by their Roman numerals:

I) Socher, M., Ellis, R. J., Wass, M., \& Lyxell, B. (2020). Comparison of Expressive Language skills in Children with Cochlear Implants and Children with Typical Hearing. Frontiers in Psychology, 11, 1405, https://doi.org/10.3389/fpsyg.2020.01405.

II) Socher, M., Larsson, E., Wass, M., Ellis, R., \& Lyxell, B. Comparing computerized inductive reasoning training in the classroom and at home: Differences in training patterns but no near or far transfer effects. Submitted manuscript under review

III) Socher, M., Ellis, R., Wass, M, \& Lyxell, B. Supervised Group Training of Analogical Reasoning in Children with Cochlear Implants: No Transfer Effects. Manuscript

IV) Socher, M., Larsson, E., Wass, M., \& Lyxell, B. The Relationship between Reasoning and Language Ability: Comparing Children with Cochlear Implants and Children with Typical Hearing. Submitted manuscript in revision

v) Socher, M., Lyxell, B., Ellis, R., Gärskog, M., Hedström, I., \& Wass, M. (2019). Pragmatic Language Skills: A Comparison of Children With Cochlear Implants and Children Without Hearing Loss. Frontiers in psychology, 10, https://doi.org/10.3389/fpsyg.2019.02243. 



\section{Introduction}

Language is a human specific skill. It enables us to share our thoughts, beliefs and desires, and to transmit information and knowledge. Using and understanding language is not trivial. The English language for example comprises of around 171,476 words which can be used to construct an infinite number of sentences with different meanings. A language takes years to learn and is often not fully mastered by a second language learner. However, if a child does not have any severe neurocognitive disabilities they will acquire language with impressive speed and without any formal training. When children reach school-age most of them are able to engage in communication both with adults and peers. They can express complex thoughts, and have acquired an impressive amount of vocabulary. However, one group that is at risk for language delay are deaf and hard of hearing (DHH) children with cochlear implants (CI). This is not only true for children with CIs that have additional neurocognitive disabilities (Holt \& Kirk, 2005; Meinzen-Derr et al., 2011) but also for children with CIs without any additional disability (Boons et al., 2013; Geers et al., 2009; Lund, 2016). The most likely explanation for this is that the spoken language acquisition of children with CIs is negatively influenced by both language deprivation and reduced input quality.

Most DHH children are born to hearing parents (Mitchell \& Karchmer, 2004) who are not able to use sign-language. Therefore, language exposure for many $\mathrm{DHH}$ children begins when their first CI is turned on. The preceding time of language deprivation might be one explanation for the language delays seen in children with CIs (Hall et al., 2019). A second explanation for language delays might be that the input from a CI is more sparse compared to typical hearing (TH) (Loizou, 2006). This might make spoken language acquisition, as well as spoken language use, more cognitively demanding as more top-down processes are needed to interpret the incoming sound (Rönnberg et al., 2013). Many children with CIs have varying degrees of language delays when they start formal education (at age 6 in Sweden) (Geers et al., 2009; Hansson et al., 2018). This is problematic as language abilities influence the child's ability to take part in school classes and to communicate with peers. In addition, verbal skills before school entry have been found to predict later academic outcome (Kurdek \& Sinclair, 2000).

How children are able to acquire language has been widely discussed in the literature and emergentist approaches to language acquisition and processing are on the rise. One of these approaches is the usage-based model of language acquisition, which assumes that language is learned through and by its usage (Behrens, 2009; Tomasello, 2000). Children want to understand the mean- 
ing of an utterance, they want to know what the conversational partner is trying to communicate (Tomasello, 2000). They are not interested in learning one specific word or one specific grammatical structure. They want to be able to transmit and understand messages. In usage-based models of language acquisition, as in all emergentist approaches, it is assumed that children learn language from the input they receive. General cognitive processes are thought to lead to the understanding of more and more words, and more and more complicated grammatical structures (Behrens, 2009; Tomasello, 2000). Within the usage-based models it has been assumed that social cognition, working memory (WM) and analogical reasoning (in Behrens (2009) referred to as: generalisation mechanisms) are the most important cognitive skills in language acquisition (Behrens, 2009).

When acquiring a language, children have to detect patterns, rules and regularities. This is done by analogical reasoning. Analogical reasoning refers to the ability to apply the relational structure of one object to another (Gentner \& Smith, 2012; Gust et al., 2008). Several studies suggest that analogical reasoning is an important skill for language acquisition (Childers et al., 2016a; Childers \& Tomasello, 2001; Gentner \& Christie, 2010; Gentner \& Hoyos, 2017; Gentner et al., 2007; Gentner \& Namy, 2006; Gerken, 2006, 2010; Leroy et al., 2014; Leroy et al., 2012; Marcus, 1999; Sandhofer, 2001). In addition, studies indicate that analogical reasoning ability is a trainable cognitive skill (Klauer \& Phye, 2008; A. Lenhard \& Lenhard, 2011) and that improvements in analogical reasoning transfer to language ability (Marx, 2006; Marx et al., 2010). Children with CIs could potentially profit from such a training. However, analogical reasoning training has not yet been evaluated with children with CIs.

The connection between analogical reasoning and language ability is not unidirectional. Studies show that language ability is of importance for complex analogical reasoning tasks (Baldo et al., 2010; Baldo et al., 2015; Gentner, 2016; Gentner \& Christie, 2010; Krzemien et al., 2017). Baldo et al. (2005) argue that inner speech is of importance for complex cognitive tasks, while Gentner (2016) argues that language enables us to represent relations and, by extension, improves analogical reasoning ability.

If language ability influences analogical reasoning ability this would mean that children with CIs, who are at risk for language delays, are also at risk for delays in terms of analogical reasoning ability. This is in accordance with studies finding that children with CIs perform more poorly on analogical reasoning tasks (Cejas et al., 2018), especially in the verbal domain (Edwards et al., 2011). This is problematic as analogical reasoning ability is essential for learning and creativity (Gust et al., 2008) as well as for language acquisition (Gentner \& Namy, 2006), and pragmatic language ability (Loukusa et al., 2007). Problems in the analogical reasoning domain might therefore have widespread effects on communication as well as learning abilities.

The focus of this thesis is the language and analogical reasoning ability of 
DHH children with CIs who use spoken language as their main communication mode. The aim is to evaluate performance levels as well as associations between language and analogical reasoning ability. This thesis focusses on children with CI using spoken language for communication. Therefore all language terms refer to spoken language.

\subsection{Analogical Reasoning}

Analogical reasoning refers to the ability to use similarities between relational structures of objects or situations to infer missing information (Gentner \& Smith, 2012; Gust et al., 2008). Two examples are given in Figure 1. In the verbal example, the sentence "Puppy is to dog" is the source, whose relational structure (baby animal to adult animal) is used to infer the missing information in the target: "kitten is to ...". Analogical reasoning has been found to be important for learning and creativity (Gust et al., 2008), language acquisition (Gentner \& Namy, 2006), and pragmatic language ability (Loukusa et al., 2007).

In research a distinction is often made between verbal and non-verbal analogical reasoning. Examples of both types of analogical reasoning are given in Figure 1. Both verbal and non-verbal analogical reasoning tests are often used in intelligence testing. Some intelligence tests, like the Raven's Matrices (Raven \& Court, 1938), rely only on the measurement of non-verbal analogical reasoning.

Verbal

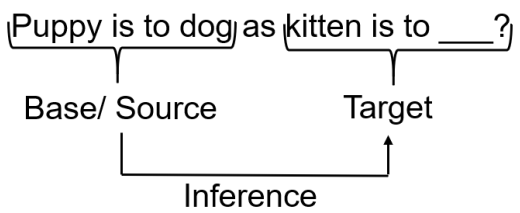

Non-Verbal
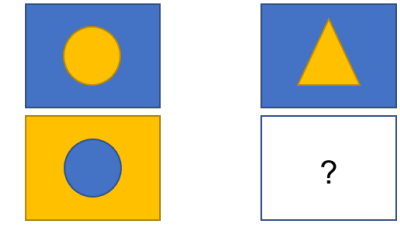

Base/ Source

Target

Inference

Figure 1: An example of a verbal and a non-verbal analogical reasoning task.

\section{Sub-processes}

Three sub-processes Retrieval, Mapping and Evaluation are needed for analogical reasoning according to Gentner and Smith (2012).

To engage in analogical reasoning, potential analogies need to be retrieved 
from long-term memory. The analogy retrieved from memory is the source which is used to explain relations in the target situation. For most analogical reasoning tests these retrieval processes are not needed as the source analogies are often provided (for example in intelligence testing).

Mapping processes are the core processes of analogical reasoning, according to Gentner and Smith (2012). The mapping process is divided into two subprocesses: alignment and inference. To solve an analogy, the similarities of the relational structure of the source and target need to be aligned. If parts of the relational structure found in the source are missing in the target, those will be filled in via inference. In the verbal analogy in Figure 1 the relational structure of the source (Puppy - Dog) would be evaluated first. In this example the relational structure of the base is: "baby $->$ adult". Next, the similarities between "Puppy" (first item in source) and "Kitten" (first item in target) can be evaluated. This process is called alignment. For "puppy" and "kitten" similarities are for example that both are baby mammals, pets, they usually have fur, four legs, and a tail. In a next step the relational structures of the source and target are compared and aligned. The target sentences has the relational structure "baby -> adult". Therefore from the similarities between "puppy" and "kitten" being a baby is picked to align the first half of the relational structure of the source and target. To complete the relational structure in the target to "baby -> adult" the word "cat" is filled in to solve the analogy. This last step is referred to as inference process.

The last sub-process of analogical reasoning is evaluation (Gentner \& Smith, 2012). Several factors are taken into consideration during this process. If possible, the factual correctness of the inference will be checked. The adaptability will be evaluated. This means that those inferences which can be more easily modified and integrated into the target situation will be accepted. In addition, those inferences that lead to the highest gain in knowledge will be preferred over those that lead to less gain in knowledge.

\section{Relational Integration}

In order to solve a complex analogical reasoning task relational integration needs to be used. Relational integration refers to the ability to integrate two or more mental representation into one (Chuderski, 2014; Dauvier et al., 2014). In the non-verbal analogy in Figure 1 for example, the vertical (change of color) and the horizontal (change of shape) dimension need to be integrated to solve the analogy. To be able to do this, both the mental representation of the vertical dimension and the mental representation of the horizontal dimension need to be kept in mind. In addition, they need to be manipulated in mind in order to integrate them into one joint mental representation of the relational structure of the analogy. This process relies on working memory (Cho et al., 2007; Chuderski, 2014; Kane et al., 2004; Süß et al., 2002), the ability to 
maintain and manipulate information in mind (Baddeley, 2012; Baddeley \& Hitch, 1994; Diamond, 2013).

\subsection{Language and Analogical Reasoning}

Gentner and Christie (2010) argue that analogical reasoning and language have a reciprocal relationship. Analogical reasoning is an important skill for generalization and categorization, two abilities that are essential for language learning according to usage-based models of language acquisition (Behrens, 2009; Tomasello, 2009). Language, on the other hand, has been found to boost analogical reasoning ability (Baldo et al., 2010; Gentner, 2016). Gentner (2016) attributes this to two factors: Language invites comparison and can be used as a symbolic system for relational comparison.

\section{Usage-based model of language acquisition}

The usage-based model of language acquisition assumes that children are able to acquire language from the language input they receive using general cognitive functions (Behrens, 2009; Tomasello, 2009). Tomasello (2009) argues that language acquisition can only be understood starting with the process of communication. He argues that children do not aim to understand single words or specific syntactical constructs, but want to understand what a speaker wants to communicate with an utterance. To do so, a child needs to first understand the overall function of the utterance and then, in a second step, the functions of the sub-components of the utterance. Two important cognitive functions for this are intention-reading and pattern finding (Tomasello, 2009). Intention reading refers to the ability to understand the common ground of a conversation and to use joint attention. Pattern finding is essential to generalize syntactical structures from the language input. Children have to compare patterns in the language and extract abstract rules from these comparisons. Pattern finding is part of the alignment process during analogical reasoning. The theoretical claims made in the usage-based models of language acquisition therefore fit to experimental studies showing the importance of analogical comparison processes for language acquisition (Gentner \& Namy, 2006). Analogical comparison processes have been found to be important for grammar acquisition (Childers \& Tomasello, 2001; Gentner \& Hoyos, 2017; Gerken, 2010; Marcus, 1999), the development of semantic categories (Gentner \& Namy, 1999) and the learning of verb meanings (Childers et al., 2016b).

\section{Analogical Reasoning Training}

If analogical reasoning is of importance for the acquisition of grammar and the construction of semantic categories (Gentner et al., 2007; Gentner \& Namy, 1999; Gómez \& Gerken, 2000), it could be argued that improving analogical 
reasoning ability should boost language acquisition. Research by Marx (2006) and Marx et al. (2010) indicates that this is the case.

Previous research suggests that analogical reasoning can be improved by means of cognitive training (Klauer \& Phye, 2008). Marx (2006) tested the effect of such an analogical reasoning training on language ability and compared the effects to a language training. Marx (2006) found that both the analogical reasoning training and the language training significantly improved language ability. In contrast, analogical reasoning ability was only improved by the analogical reasoning training. Marx (2006) assumed that this was due to the analogical reasoning training leading to paradigmatic transfer. Paradigmatic transfer refers to transfer effects from a cognitive training to skills that rely on the trained skill. In the case of analogical reasoning training this means that improving analogical reasoning ability should lead to effects on language acquisition. This is also in accordance with results reported by Marx et al. (2010). They also found effects of analogical reasoning training on different language abilities, even when the training was conducted by kindergarten teachers instead of a specially trained test leader. However, the improvement might be explained by the fact that abilities which are improved via analogical reasoning training, like generalisation, are also needed for the language tasks used by Marx (2006) and Marx et al. (2010). This means an effect of the training cannot necessarily be attributed to enhanced language acquisition ability.

\section{Pragmatic language ability}

Pragmatic language ability refers to the ability to use language in a social context. It is a complex skill including the ability to use language in a flexible way, the ability to integrate information from different sources, and the ability to plan a response while comprehending an utterance.

To engage in a successful conversation the speaker needs to be able to adapt their language to the needs of the listener. For example using easier terms when speaking to a small child. Therefore, the ability to use language in a flexible way is an important ability for a successful conversation. This ability requires the speaker to have a high language competence. The speaker needs a large vocabulary and needs to know simple, as well as complex grammatical structures. In accordance with this, strong associations have been found between grammar, vocabulary and pragmatic language ability in typically developing children (for a review, see: (Matthews et al., 2018)).

Sentences are often incomplete and/or indirect in natural conversations. According to the Relevance Theory all relevant information is taken into consideration by the listener. The listener subsequently chooses the first relevant interpretation that meets their expectation (Sperber \& Wilson, 2004). The real meaning of an utterance is therefore constructed by drawing inferences from the literal meaning, the contextual information, non-verbal gestures, 
facial expressions and intonation. Drawing inferences is a sub-process of analogical reasoning ability. Therefore, analogical reasoning is an important skill for the interpretation of language (Loukusa et al., 2007). In accordance with this, associations have been found between both non-verbal analogical reasoning and pragmatic language ability (Turkstra et al., 1996) and between verbal analogical reasoning and pragmatic language ability (Loukusa et al., 2007) in typically developing children.

During a conversation a person has to switch between being the listener and the speaker. This is referred to as turn-taking. Turn-taking is a demanding process. The own response needs to be planned while comprehending the utterance of the speaker (Levinson, 2016). The short time gap between turns found in natural conversation indicate that the listener is not waiting until the end of the speaker's utterance to plan their own response (Corps et al., 2018; Levinson, 2016). Levinson (2016) argues that the listener predicts the meaning of the utterance while it is still ongoing. How these predictions are achieved is still unclear. However, it has been suggested that the listener uses inferences (Levinson, 2016). Those inferences might be drawn by taking into account all information available, such as the literal meaning, the context, and the intonation. The importance of inference making for turn-taking is in accordance with research showing associations between verbal analogical reasoning and pragmatic language ability (Loukusa et al., 2007).

\section{The influence of language ability on analogical reasoning}

Analogical reasoning and language ability have a reciprocal relationship. This means, analogical reasoning processes are important for language acquisition and use, but language ability also influences analogical reasoning ability (Gentner \& Christie, 2010). While this is not surprising for verbal analogical reasoning, this is also the case for non-verbal analogical reasoning (Baldo et al., 2010; Baldo et al., 2015; Cejas et al., 2018; Krzemien et al., 2017).

A reason why non-verbal analogical reasoning ability has been found to be influenced by language ability might be that a higher language ability improves relational integration ability. The knowledge of relational language makes it possible to verbalize the relations that need to be integrate. This might reduce the working memory demands and thereby improve the ability to solve complex analogical reasoning tasks. This hypothesis is supported by findings showing that the knowledge of relational language improves analogical reasoning ability (Gentner, 2016). In addition, it is in accordance with Baldo et al. (2005), who argue that complex cognitive tasks are supported by language through inner speech. They suggest that covert verbalization might help to manipulate concepts in mind. 


\subsection{Children with Cochlear Implants}

A CI is a device which converts sound into an electrical signal which is then transmitted to the auditory cortex. CIs are used for a hearing loss caused by malfunctions in the inner ear, often referred to as sensorineural hearing loss (Gelfand, 2009).

A CI is recommended for a severe $(61-80 \mathrm{~dB})$ to profound $(>81 \mathrm{~dB})$ hearing loss which cannot be restored using a traditional hearing aid (Gravel \& O'Gara, 2003). CIs are used in hearing rehabilitation both for congenital (from birth) and acquired hearing loss. In childhood, the main cause of acquired sensorineural hearing loss is infection (e.g. meningitis, cytomegalovirus $(\mathrm{CMV}))$. The main causes of congenital hearing loss are genetic factors, including both syndromes and genetic mutations which only affect hearing (Korver et al., 2017). The prevalence of permanent bilateral hearing loss is 1.33 per 1000 live births and increases to 2.83 per 1000 for children in primary school according to data from the UK (Fortnum et al., 2001; Korver et al., 2017). In most developed countries, newborn hearing screening is used and congenital hearing loss is usually detected early on (Korver et al., 2017). Therefore, the age at which children are typically fitted with a CI has been reduced and many children get their implants before the age of one (Korver et al., 2017). Modern CIs work like a vocoder, which processes the incoming sound and splits it into spectral bands. The information from these bands is transmitted to the brain via electrodes stimulating the neural fibres of the cochlea (Cucis et al., 2018). However, some information from the incoming sound is lost. The input provided by a CI is more sparse than in TH. Compared to TH, frequency resolution is poorer (Loizou, 2006) and the dynamic range (Zeng, 2004) is reduced. Therefore, having a CI enables children with a severe to profound hearing loss to regain access to spoken language and other sound input, but the input quality is not comparable to TH.

Most children with CIs are born to hearing parents (Mitchell \& Karchmer, 2004). As most hearing parents are not able to use sign language many families rely on oral communication. This means, however, that children with CIs are often susceptible to a phase of language deprivation early in life, before they receive their implants. Hall et al. (2019) argue that language deprivation early in life as well as the reduced perceptual quality of the language input results in language delays in children with CIs. It has been found that children who receive their CI before they are one year old have better language outcomes than children who receive their implants later (Dettman et al., 2016; Karltorp et al., 2020; May-Mederake, 2012). This might be due to a shorter duration of language deprivation and the fact that children implanted before the age of one receive spoken language input within the sensitive/critical period of phonology (Ruben, 1997). Studies show that phonological skills are associated with language ability (Dillon et al., 2004; Sundström et al., 2018; 
Willstedt-Svensson et al., 2004) and orthographic learning (Wass et al., 2019) of children with CIs.

\section{Language Ability}

Children with CIs are at risk for language delays that are often still prevalent when the children reach school-age (Geers et al., 2009)). These delays are most likely explained by language deprivation early in life and a reduced perceptual quality of the language input. In addition, the variation in terms of language ability is larger in children with CI compared to peers with $\mathrm{TH}$ (Chilosi et al., 2013; Hess et al., 2014). This might be explained by a greater importance of cognitive abilities for the language ability of children with CIs compared to children with $\mathrm{TH}$.

If the quality of the sound input is reduced, top down processes are needed for language comprehension (Hannemann et al., 2007; Rönnberg et al., 2013). If the incoming signal does not match the information saved in the semantic long-term memory, cognitive processes are needed to solve this mismatch. Rönnberg et al. (2013) argue that WM dependent processes are used to infer the missing information from the sound signal. Having a CI leads to persistent sub-optimal listening conditions and cognitive factors might therefore be of greater importance when acquiring and using language with such a device. Accordingly, research by Kronenberger et al. (2014) and Kronenberger and Pisoni (2019) shows that WM is more strongly associated with the language ability of children with CIs compared to children with TH. In addition, Meinzen-Derr et al. (2011) found that children with CIs who have developmental delays perform more poorly on spoken language measures compared to children with TH matched for age and cognitive abilities. This might be explained by a greater cognitive demand for acquiring spoken language with a CI. This is also in accordance with results by Werfel and Hendricks (2016). The authors showed that cognitive fatigue ratings of children with CIs are associated with their language and speech perception ability. This might be due to the fact that many of the available cognitive resources have to be used for language processing, especially for those children with CIs with weaker language abilities.

Individual variation in cognitive ability might have a larger effect on the language ability of children with CIs than on the language ability of children with TH. However, there are factors, such as the age at implantation, the duration of language deprivation, type of implant, or communication mode at home and in school, which further influence the language ability of children with CIs. These additional factors might as well explain why a larger variation in language ability has been found in children with CIs compared to children with TH.

Two abilities that are essential to actively participate in communication are expressive and pragmatic language skills. In order to communicate with other 
people, it is not only important to understand what someone is saying, but also to be able to express own thoughts, beliefs and desires. In addition, it is important to be able use language in a social context, which for example means to take contextual information into consideration. Both expressive and pragmatic language ability are fundamental abilities for participation. The focus of this thesis in terms of language ability are therefore the expressive and pragmatic language ability of children with CIs.

\section{Expressive Language}

Expressive Language can be divided into expressive vocabulary, the ability to use a variety of words, and expressive grammar, the ability to use complex grammatical structures. Both expressive vocabulary (Lund, 2016) and expressive grammar (Boons et al., 2013) have been found to be delayed in children with CIs. In addition, studies show a larger variation in terms of expressive language ability in children with CIs compared to children with TH (Chilosi et al., 2013; Hess et al., 2014). However, in most studies the children with CIs and children with $\mathrm{TH}$ have not been matched on cognitive abilities. It is therefore possible that the differences in expressive language skills have been either over- or underestimated.

Children with CIs often start language acquisition later than children with TH. Lund (2016) argues that as vocabulary grows throughout life, it is hard to catch up on a delay. For grammar on the other hand, it should be easier to catch up, as children with typical development will have acquired all grammatical rules of the language at one point. However, research by Boons et al. (2013) indicates no systematic weaker or stronger expressive language domain in children with CIs. They found children with CIs to perform more poorly not only on expressive vocabulary but also on expressive grammar measures. In addition, Boons et al. (2013) found that children with CIs make severer grammatical errors compared to children with $\mathrm{TH}$, even if they perform within two standard deviations of their age norm. Therefore, even if the children with CIs make an age appropriate number of errors, those errors might lead to more disruptions in communication. However, in the study by Boons et al. (2013) the comparison groups have not been matched on cognitive abilities.

The expressive language ability of children with CIs has been found to be associated with cognitive abilities, such as non-verbal intelligence (Cupples et al., 2018). This is both in accordance with results found for children with TH (van der Schuit et al., 2011) and the usage-based model of language acquisition (Behrens, 2009; Tomasello, 2009). Non-verbal intelligence measures are in large parts relying on analogical reasoning tasks (e.g. the Raven's matrices). Therefore, a connection between non-verbal intelligence and language ability in children with CIs might be explained by the influence of analogical reasoning ability on language acquisition. If analogical reasoning is of impor- 
tance for language acquisition, those children with better analogical reasoning skills would be expected to have higher expressive language abilities. However, the influence of cognitive skills, such as analogical reasoning ability, is often not taken into consideration when comparing the expressive language skills of children with CIs and children with TH. While children with an non-verbal IQ below a certain number (e.g. 80) are often excluded (see for example: Boons et al. (2013), Chilosi et al. (2013), Geers et al. (2009)), comparison groups are seldom matched on cognitive abilities. Therefore differences in expressive language, both in terms of average performance and variation, between children with CIs and children with TH could in parts be explained by differences in cognitive abilities.

\section{Pragmatic Language ability}

Pragmatic language ability is the ability to use language in a social context. It is essential in order to engage in conversations, and has been suggested to depend both on language and cognitive abilities in children with TH (Matthews et al., 2018). Children with CIs have been found to perform more poorly than children with $\mathrm{TH}$ on several pragmatic language measures (Most et al., 2010; Toe \& Paatsch, 2013). Verbal analogical reasoning has been found to be associated to the pragmatic language ability of children with TH (Loukusa et al., 2007). As children with CIs have been found to perform more poorly on verbal analogical reasoning tasks compared to children with TH (Edwards et al., 2011), this might explain some of the differences in terms of pragmatic language ability seen between the groups.

The reasons children with CIs perform more poorly on pragmatic language measures have only been discussed in a few studies (Jeanes et al., 2000; Most et al., 2010). Most et al. (2010) assume that several factors might be responsible for a pragmatic language delay in children with CIs. Delays in expressive language might lead to children being less able to use language in a flexible way (for example adapting to the needs of the listener). Reduced audibility of linguistic cues (intonation) might lead to missing the end of a turn or being unable to detect the emotion the conversational partner was intending to transfer with the utterance. Theory of mind (ToM), the ability to know about your own and others' mental states, is an important skill for social communication. A delay in ToM might lead to additional problems. Previous studies have shown that some children with CIs are delayed in terms of their ToM (Ketelaar et al., 2012; Liu et al., 2018), especially those that receive their CI late (Sundqvist et al., 2014). Further, both Most et al. (2010) and Jeanes et al. (2000) argue that less possibility to practice pragmatic language skills might lead to a delayed development in children with CIs. However, no study has looked into the cognitive factors influencing the pragmatic language ability of children with CIs.

A study by Loukusa et al. (2007) with children with TH shows an associ- 
ation between verbal analogical reasoning and pragmatic language ability . Loukusa et al. (2007) argue that verbal analogical reasoning is an important skill to use language in a flexible way. In addition, the ability to make verbal inferences (a sub-process of verbal analogical reasoning) is likely connected to turn-taking ability (Levinson, 2016).

Ibertsson et al. (2009) and Paatsch and Toe (2014) found that children with CIs tend to have longer turns in a conversation. Ibertsson et al. (2009) in addition found that children with CIs use more requests for additional information. Both these behaviours can be interpreted as a tendency to control a conversation. Paatsch and Toe (2014) argue that children with CIs are trying to avoid conversation breakdowns. However, the behaviour could also be due to problems with turn-taking. Most et al. (2010) found that children with CIs or hearing aids (HAs) show problems in the ability to maintain the topic of a conversation and do often not add new and relevant information during their turn. In addition, Most et al. (2010) found that children with CIs or HAs often make a pause before responding to an utterance. It might be the case that these findings are due to the demanding nature of the turn-taking process, in which both comprehension and production preparation are needed at the same time (Levinson, 2016). To be able to prepare a response while still listening to an utterance the child needs to predict the meaning of the utterance before it ends. It might be that children with CIs are more likely to miss acoustical cues which are important for these predictions (e.g: hearing if an utterance is a question). In addition, their ability to make verbal inferences might be associated with the ability to predict the meaning of an utterance and therefore with their turn taking ability. It has until now not been studies if the pragmatic language ability of children with CIs is associated to their verbal analogical reasoning skills.

\section{Cognitive Ability}

While much of the research on children with CIs focuses on language development. It has also been argued that having a CI influences cognitive abilities. However, while Conway et al. (2009), Kral et al. (2016) and Kronenberger (2019) argue that auditory deprivation influences cognitive development, Hall et al. (2019) argue that language deprivation influences the cognitive abilities of children with CIs. Reduced access to language is likely to lead to language delays, especially if language is learned from the input and by its usage, as is argued in the usage-based model of language acquisition (Behrens, 2009). Performance on verbal cognitive tasks is potentially influenced by language delays, as is performance on non-verbal cognitive tasks which encourage verbal strategies.

In many studies on children with CIs verbal cognitive measures are used. These measures tap into language skills and children with CIs are often delayed in terms of their language ability. Therefore, they may be expected 
to perform more poorly compared to peers with $\mathrm{TH}$, a finding observed in a number of studies (Akçakaya et al., 2019; Edwards et al., 2011; Nittrouer et al., 2017; Pixner et al., 2014).

Language ability of importance for non-verbal cognitive measures that benefit from verbal strategies. In accordance with this, Davidson et al. (2019) found that children with CIs perform more poorly than children with TH on a nonverbal reasoning task if verbal labels can be used for the stimuli. In addition, studies on implicit sequence learning show a poorer performance of children with CIs for tasks which encourage verbal strategies (Conway et al., 2011), but not for tasks which do not encourage such strategies (von Koss Torkildsen et al., 2018).

Few studies have focused on analogical reasoning ability of children with CIs (Akçakava et al., 2018; Cejas et al., 2018; Davidson et al., 2019; Edwards et al., 2011). Analogical reasoning is an important cognitive skill, which has been found to be connected to language acquisition (Childers et al., 2016a; Childers \& Tomasello, 2001; Gentner \& Namy, 2006; Marcus, 1999), pragmatic language ability (Loukusa et al., 2007), and to learning and creativity (Gust et al., 2008). However, analogical reasoning is also a skill that has been argued to be influenced by language ability (Gentner \& Christie, 2010). The aim of this thesis is to provide more data to help untangle the relationship between language and analogical reasoning ability and to evaluate whether differences between children with CIs and children with TH are due to differences in language ability.

\section{Verbal Analogical reasoning}

Children with CIs have been found to perform more poorly on verbal analogical reasoning tasks compared to peers with TH (Edwards et al., 2011). Studies by Edwards et al. (2011) and Aslan and Yücel (2019) indicate that this is mostly likely due to differences in language ability. Both grammar and vocabulary skills seem to be associated to the verbal analogical reasoning ability of children with CIs (Aslan \& Yücel, 2019; Edwards et al., 2011). Results by Akçakaya et al. (2018) indicate that phonological WM (non-word repetition) influences the verbal analogical reasoning skills of children with CIs. However, this relationship seems to be mediated by receptive and expressive language ability. Those children with CIs that had better non-word repetition skills were found to have higher language ability which in turn positively influenced verbal reasoning. However, no study has investigated if children with CIs perform comparably in terms of verbal analogical reasoning to children with TH matched for language ability. It is therefore unclear if children with CIs have verbal analogical reasoning skills that would be predicted by their language proficiency. 


\section{Non-verbal analogical reasoning}

The results in terms of the non-verbal analogical reasoning ability of children with CIs are mixed. Davidson et al. (2019) found that children with CIs perform more poorly on non-verbal analogical reasoning task in which verbal labels can be used for the stimuli. However, if no verbal labels could be used the performance of the children with CIs and the children with TH did not significantly differ on a non-verbal analogical reasoning task (abstract matrix reasoning). In contrast, Cejas et al. (2018) found, that children with CIs perform more poorly on a abstract matrix reasoning task (non-verbal analogical reasoning) compared to peers with TH. Although Cejas et al. (2018) used a task for which verbal strategies like verbal labelling are unlikely to be used, they found language ability to be the most important predictor for the non-verbal analogical reasoning ability of children with CIs and children with TH. This is in accordance with research on patients with aphasia (Baldo et al., 2010; Baldo et al., 2015) and research by Gentner (2016), indicating that complex non-verbal analogical reasoning is supported by language.

\subsection{Summary}

Children with CIs tend to have delays in terms of their language abilities compared to peers with TH. Both language deprivation and reduced input quality might be responsible for this. The poorer input quality might lead to an increased importance of cognitive skills for language understanding, production and acquisition. However, it has not yet been investigated if training analogical reasoning, a cognitive ability which is important for language acquisition, leads to language improvements in children with CIs.

It has been argued that either language or auditory deprivation lead to delays in cognitive abilities in children with CIs. It might therefore be the case that analogical reasoning is delayed for children with CIs which might lead to disadvantages in terms of language acquisition. However, some studies indicate that language ability is of importance for analogical reasoning and differences found between children with CIs and children with TH might therefore be explained by differences in language ability.

Even though many studies have concentrated on the language abilities of children with CIs only few studies have focused on pragmatic language ability. Pragmatic language ability has been argued to be influenced both by grammar and vocabulary skills and verbal analogical reasoning ability in typical development. As these skills have been found to often be delayed in children with CIs they might have specific problems in the pragmatic language domain which might negatively influence social communication. 


\subsection{General Aims and Study Rationale}

The aim of the current thesis was to investigate the language and analogical reasoning ability of children with CIs in comparison to children with TH. In addition, the aim was to analyse the association between those two skills. The hypotheses of the thesis are presented in Figure 2 .

The aim of Study I was to compare the expressive language of children with CIs and children with TH. The aim was further to evaluate if the variance in terms of expressive language ability is larger in children with CIs compared to children with TH even when the groups are matched on analogical reasoning and WM ability. The aim of study II and III was to evaluate if an analogical reasoning training leads to transfer effects on language ability for children with TH and children with CIs. The aim of study IV was to analyse the relationship between language and analogical reasoning ability. The aim was to investigate if differences in terms of analogical reasoning ability between children with CIs and children with $\mathrm{TH}$ are explainable by differences in language ability. The aim of study $\mathrm{V}$ was to compare the pragmatic language ability of children with CIs and children with $\mathrm{TH}$ and to analyse associations between verbal cognitive measures and pragmatic language ability in both groups.

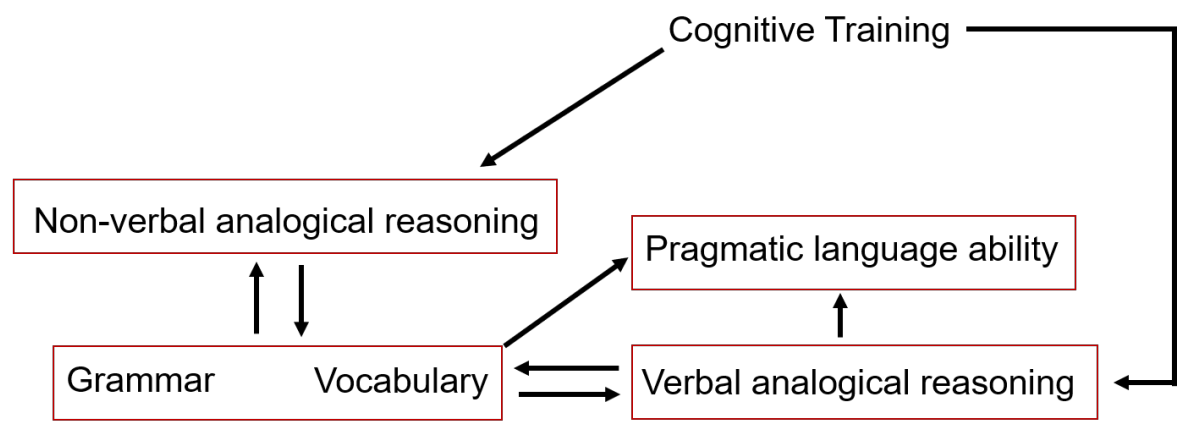

Figure 2: A graphical representation of the expected result pattern. For the abilities marked in red, differences in performance were expected between children with CIs and children with $\mathrm{TH}$. Both grammar and vocabulary refer to spoken language. 



\section{Empirical Studies}

\subsection{General Method}

\section{Recruitment of Participants}

The children with CIs were recruited at two different time points, and the children with $\mathrm{TH}$ were recruited at three different time points. The first recruitment of children with CIs led to a sample of seven children with CIs. They were all from the same special school. These children participated in studies I, III, IV and V. The second recruitment of children with CIs led to an increase in sample size of an additional ten children with CIs. The children were recruited via a hearing clinic in Stockholm. These children were part of studies I, IV and V. Two of the children are not part of paper V, as it had to be sent in before the testing was finished. A graphical representation of the recruitment process of the children with CIs is shown in Figure 3.

The children with TH were recruited via schools in Linköping and Norrköping. Informations were send to all schools with a pre-school class (children aged around 6 years). If the schools agreed on participating, the teachers were asked to pass an information letter on to the parents. The first recruitment of children with TH led to a sample of 30 children. Sixteen children were assigned to the training group and 14 children were assigned to the control group of study II. The pre-test results of all 30 children were used in studies I, IV and V. In the second round, ten additional children with TH, were recruited. These children are part of study II and study IV. In a third recruitment round, eight additional children with $\mathrm{TH}$ were recruited. These children did not participate in the cognitive training. Their results are part of studies I, IV and V. A graphical representation of the recruitment process of the children with $\mathrm{TH}$ is shown in Figure 4 .

For all participating children (CIs \& $\mathrm{TH}$ ) a consent form was signed by the parents and both children and caregivers were told that they could drop out of the study at any point without giving a reason. The study was approved by the Linköping Research Ethics Committee (dnr 2015/308-31).

\section{Participants}

Nineteen children with CIs participated in the studies included in the current thesis. One of the children had Usher syndrome, which leads to a progressive visual impairment. However, due to the age of the children the degree of the visual impairment was expected to be low. In accordance with this, no 


\section{Children with $\mathrm{Cl}$ \\ $N=17$}

\section{Winter/Spring 2018}

Recruited via the hearing clinic in

Stockholm

Recruited after the cognitive training

$N=10$

Study I, IV

Study $V(N=8)$

Study I, III, IV, V

Figure 3: A graphical representation of the recruitment process of the children with CIs.

problems with vision during testing were reported by the test leader. To our knowledge, none of the other children had any additional disability. All children with $\mathrm{TH}$ were in mainstream school. In study I the children with CIs were matched to children with $\mathrm{TH}$ in terms of non-verbal analogical reasoning ability and WM. Three children with CIs could not be matched to any children with $\mathrm{TH}$ and were therefore excluded from the study. For study III, the data of seven children with CIs was analysed. For study IV, one child had to be excluded due to missing data and one child was excluded as an outlier. Two children with CIs were not included in study $\mathrm{V}$, as their testing was not finished by the submission deadline. In addition, three children had to be excluded due to missing data which led to a sample size of 14 children with CIs for study V. In Table 1 the mean, standard deviation and range for the age of the children is displayed for both the children with $\mathrm{TH}$ and CI participating in the five studies of this thesis. For the children with CIs, the age at hearing loss detection, age at implantation and schooling (mainstream vs. special school) is reported in Table 2 . In order to protect the anonymity 


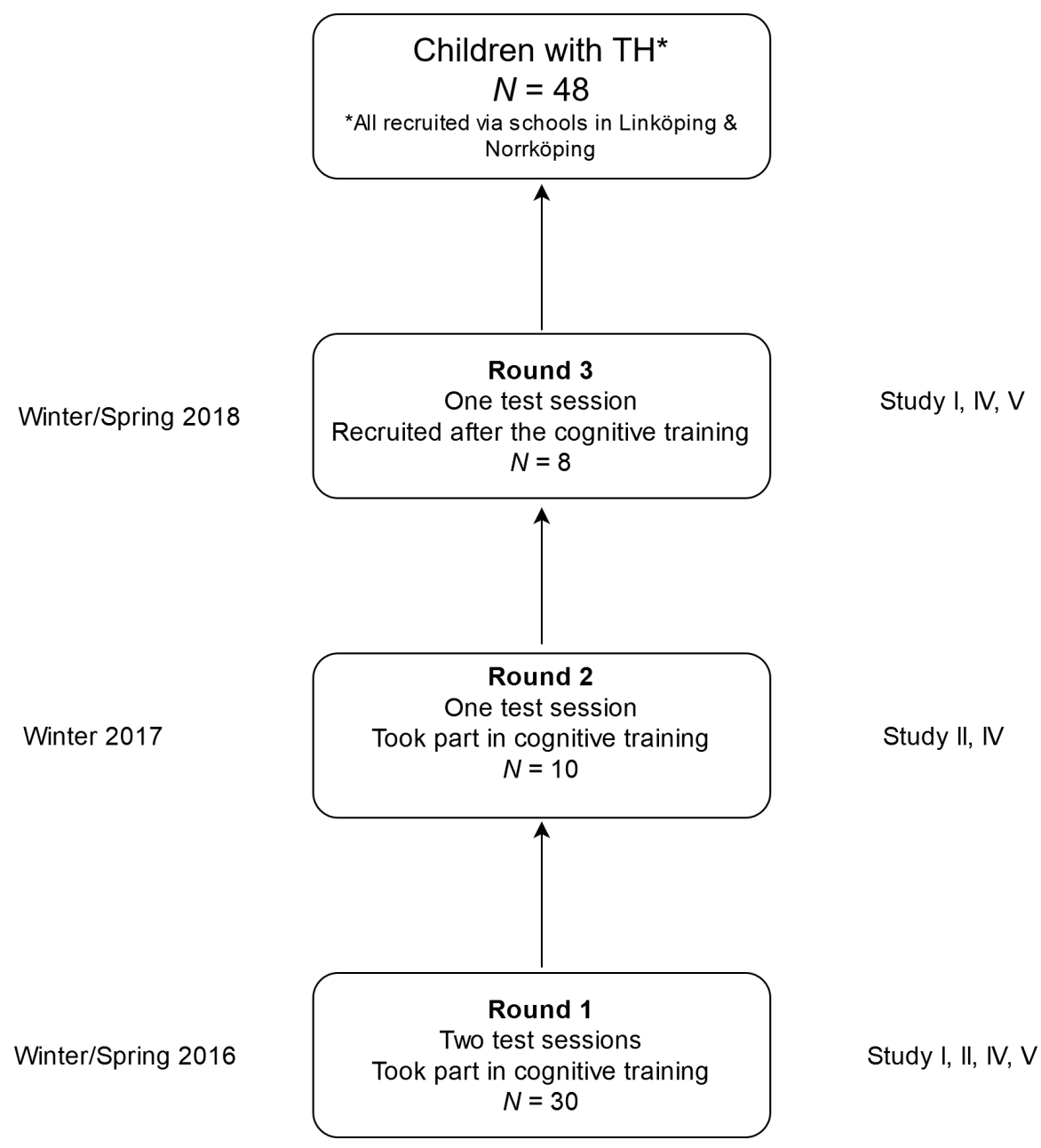

Figure 4: A graphical representation of the recruitment process of the children with TH. 
of the participants, their diagnosis (reason for deafness) is not presented in the table.

Table 1: In this table the mean standard deviation and range of the age of the children is presented for the five studies included in this thesis. For each paper the information is presented at the group level.

\begin{tabular}{|c|c|c|c|}
\hline & Mean (years) & SD (months) & Range (years) \\
\hline \multicolumn{4}{|l|}{ I } \\
\hline Children with CIs $(\mathrm{N}=14)$ & $6 ; 8$ & 11 & $5 ; 6-8 ; 2$ \\
\hline Children with $\mathrm{TH}(\mathrm{N}=14)$ & $6 ; 5$ & 4.5 & $5 ; 7-7 ; 1$ \\
\hline \multicolumn{4}{|l|}{ II } \\
\hline Children with TH (control; $\mathrm{N}=14$ ) & $6 ; 6$ & 3 & $6 ; 1-7 ; 0$ \\
\hline Children with TH (unsupervised; $\mathrm{N}=16$ ) & $6 ; 5$ & 3 & $6 ; 2-7 ; 1$ \\
\hline Children with TH (supervised; $\mathrm{N}=10$ ) & $6 ; 5$ & 4 & $6-6 ; 8$ \\
\hline \multicolumn{4}{|l|}{ III } \\
\hline Children with CIs $(\mathrm{N}=7)$ & $7 ; 6$ & 7.6 & $6 ; 6-8 ; 2$ \\
\hline \multicolumn{4}{|l|}{ IV } \\
\hline Children with CIs $(\mathrm{N}=15)$ & $6 ; 7$ & 11 & $5 ; 6-8 ; 2$ \\
\hline Children with $\mathrm{TH}(\mathrm{A}+\mathrm{L} ; \mathrm{N}=23)$ & $6 ; 5$ & 4 & $6 ; 1-7 ; 1$ \\
\hline Children with TH $(\mathrm{A} ; \mathrm{N}=23)$ & $6 ; 5$ & 4 & $5 ; 8-7 ; 3$ \\
\hline \multicolumn{4}{|l|}{ V } \\
\hline children with CIs $(\mathrm{N}=14)$ & $6 ; 7$ & 11 & $5 ; 6-8 ; 2$ \\
\hline Children with $\mathrm{TH}(\mathrm{N}=34)$ & $6 ; 5$ & 4 & $5 ; 8-7 ; 3$ \\
\hline
\end{tabular}

$\mathrm{A}+\mathrm{L}=$ matched on age and language comprehension skills; $\mathrm{A}=$ matched on age unsupervised $=$ training alone; supervised $=$ training with a parent 
Table 2: Individual data - children with CIs: The data were collected using a questionnaire which was filled in by the caregivers.

\begin{tabular}{|c|c|c|c|c|c|c|}
\hline Age & $\begin{array}{l}\text { Detection } \\
\text { Deafness }\end{array}$ & $\begin{array}{l}\text { Age at } \\
\text { First CI }\end{array}$ & $\begin{array}{l}\text { Unilateral } \\
\text { Bilateral }\end{array}$ & Language & School & Study \\
\hline $8 ; 9$ & newborn & $2 ; 0$ & $\begin{array}{l}\text { bilateral } \\
(2 ; 6)\end{array}$ & $\begin{array}{l}\text { oral } \\
(10 \% \text { sign })\end{array}$ & Special & I, III, IV, V \\
\hline $8 ; 7$ & $1 ; 0$ & $2 ; 0$ & bilateral & $\begin{array}{l}\text { oral } \\
(10 \% \operatorname{sign})\end{array}$ & Special & III, V \\
\hline $8 ; 11$ & $3 ; 8$ & $5 ; 0$ & unilateral & only oral & Special & I, III, IV, V \\
\hline $8 ; 4$ & $2 ; 6$ & $3 ; 0$ & bilateral & only oral & Special & I, III, IV, V \\
\hline $7 ; 9$ & newborn & $1 ; 0$ & $\begin{array}{l}\text { bilateral } \\
(1 ; 6)\end{array}$ & $\begin{array}{l}\text { oral } \\
\text { (sign support) }\end{array}$ & Special & I, III, IV, V \\
\hline $7 ; 4$ & $0 ; 1$ & $5 ; 6$ & unilateral & $\begin{array}{l}\text { oral } \\
(10 \% \operatorname{sign})\end{array}$ & Special & I, III, IV, V \\
\hline $6 ; 6$ & $0 ; 2$ & $0 ; 8$ & $\begin{array}{l}\text { bilateral } \\
(1 ; 8)\end{array}$ & $\begin{array}{l}\text { bilingual } \\
\text { (oral }+ \text { sign) }\end{array}$ & Special & $\mathrm{I}, \mathrm{IV}, \mathrm{V}$ \\
\hline $6 ; 3$ & newborn & $3 ; 0$ & unilateral & $\begin{array}{l}\text { bilingual } \\
\text { (oral }+ \text { sign) }\end{array}$ & Special & $\mathrm{IV}, \mathrm{V}$ \\
\hline $5 ; 8$ & $0 ; 3$ & $0 ; 7$ & $\begin{array}{l}\text { bilateral } \\
(1 ; 0)\end{array}$ & only oral & Mainstream & $\mathrm{I}, \mathrm{IV}, \mathrm{V}$ \\
\hline $5 ; 9$ & $0 ; 1$ & $0 ; 8$ & $\begin{array}{l}\text { bilateral } \\
(1 ; 6)\end{array}$ & only oral & Mainstream & $\mathrm{I}, \mathrm{IV}, \mathrm{V}$ \\
\hline $7 ; 0$ & $0 ; 6$ & $1 ; 0$ & $\begin{array}{l}\text { bilateral } \\
(1 ; 8)\end{array}$ & $\begin{array}{l}\text { oral } \\
\text { (sign as support; } \\
\text { not signing self) }\end{array}$ & Mainstream & $\mathrm{I}, \mathrm{IV}, \mathrm{V}$ \\
\hline $5 ; 8$ & $0 ; 3$ & $0 ; 7$ & $\begin{array}{l}\text { bilateral } \\
(1 ; 3)\end{array}$ & $\begin{array}{l}\text { oral } \\
\text { (sign as support) }\end{array}$ & Mainstream & $\mathrm{I}, \mathrm{IV}, \mathrm{V}$ \\
\hline $5 ; 7$ & $2 ; 0$ & $2 ; 4$ & $\begin{array}{l}\text { bilateral } \\
(3 ; 2)\end{array}$ & $\begin{array}{l}\text { oral } \\
\text { (sign as support) }\end{array}$ & Mainstream & $\mathrm{I}, \mathrm{IV}, \mathrm{V}$ \\
\hline $7 ; 0$ & $0 ; 6$ & $0 ; 9$ & $\begin{array}{l}\text { bilateral } \\
(0 ; 11)\end{array}$ & $\begin{array}{l}\text { oral } \\
\text { (sign as support) }\end{array}$ & Mainstream & $\mathrm{I}, \mathrm{IV}, \mathrm{V}$ \\
\hline $7 ; 7$ & $2 ; 0$ & $3 ; 0$ & bilateral & oral & Special & I, III, IV \\
\hline $5 ; 6$ & newborn & $0 ; 5$ & $\begin{array}{l}\text { bilateral } \\
(0 ; 9)\end{array}$ & oral & Mainstream & IV \\
\hline $5 ; 4$ & newborn & $0 ; 5$ & $\begin{array}{l}\text { bilateral } \\
(1 ; 0)\end{array}$ & oral & Mainstream & IV \\
\hline
\end{tabular}

All numbers are age in years

\section{Cognitive Tests}

For the current thesis non-verbal analogical reasoning skills, verbal reasoning skills, verbal fluency, verbal WM skills and non-verbal WM have been measured. The tests included in the studies are listed in Table 3 . 
Table 3: In this table the cognitive and language tests used in the current thesis are listed. It is also indicated in which studies the results from the tests have been used

\begin{tabular}{llll}
\hline Cognition & & & \\
& Matrix test(WNV) & $\begin{array}{l}\text { Non-verbal } \\
\text { analogical reasoning } \\
\text { Non-verbal } \\
\text { analogical reasoning }\end{array}$ & I, II, \\
& Animalogica & Verbal & II, III, IV \\
& Spoken Analogies (ITPA) & II, III, \\
& Sentence Completion and Recall (SIPS) & Verbal WM & IV, V \\
& Visual Matrix Patterns (SIPS) & Non-verbal WM & I, V \\
\hline \multirow{2}{*}{ Language } & & I \\
\hline & TROG-2 & Receptive spoken grammar & II, IV, V \\
& Stories & Story comprehension & III \\
& Animal task & Semantic Verbal fluency & II, III, V \\
& FAS task & Phonological verbal fluency & II, III \\
& Expressive Vocabulary (CELF-IV) & Expressive vocabulary & I, V \\
& Formulate Sentences (CELF-IV) & Expressive grammar & I \\
& Pragmatics Profile (CELF-IV) & Pragamtic language & V \\
\hline
\end{tabular}

\section{Non-verbal reasoning}

Non-verbal analogical reasoning ability was measured with a standard measure, the Matrix test from the Wechsler Nonverbal Scale (WNV) test battery (Wechsler \& Naglieri, 2007). In study I, the Matrix task is referred to as a non-verbal intelligence measure. The child saw a matrix of abstract patterns with one pattern missing and was asked to fill in the missing pattern. The answer format was multiple choice and the child was asked to point at the correct answer. For each correct answer, the child received one point. The test was terminated if the child gave the wrong answer to four out of five consecutive trials. The first trials could be solved via pattern matching, whereas from the 9 th trial relational integration was needed. The total number of trials for the Matrix test was 35 and therefore the maximum possible score was 35 . The task took around 10-15 minutes. 


\section{Non-verbal reasoning; high relational integration demand}

Animalogica was used to measure non-verbal analogical reasoning ability with higher relational integration demand. Animalogica was developed by Stevenson et al. (2013). The original version is in Dutch and the test was translated to Swedish for this thesis. For the translation processes, Claire Stevenson provided the author of this thesis with the test material in English. The English material was then translated to Swedish by a Swedish native speaker. The translated sentences were recorded, spoken by a female Swedish native speaker and sent to Claire Stevenson, who used them to make a Swedish version of the Animalogica test.

Animalogica was conducted on a laptop. On the screen the child saw a $2 \times 2$ grid and was asked to fill the empty grid with animals in order to "solve the puzzle". The animals presented in the three non-empty grids varied in size, kind, position in the cell, colour and viewing direction. An example trial from Animalogica is shown in Figure 5. The total number of trials was 24 and therefore the maximum possible score was 24. The task took around 25-30 minutes. For a more detailed description of the task see Paper IV.

\section{Verbal Reasoning}

Verbal reasoning ability was assessed using verbal analogies subtest from the Illinois test of psycholinguistic abilities (ITPA) battery (Hammill et al., 2013). In this test, the child was asked to fill in a missing word in order to solve a verbal analogy of the form: A dad is big, a baby is (?). For every correctly solved analogy the child received one point. The task was terminated if the child answered three consecutive trials wrongly. The total number of trials was 25 and therefore the maximum possible score was 25 . The task took around 5-10 minutes.

\section{Verbal Fluency}

Both a semantic and phonological verbal fluency task were used (Benton et al., 1978). For the semantic verbal fluency task, the category 'animal' was chosen and the child was asked to name as many animals as possible within one minute. For the phonological fluency task, the child was asked to produce as many words as they know starting with F, A and S. For each letter, the time limit was one minute.

\section{Verbal WM}

Verbal WM was assessed with help of the sentence completion and recall task from the Sound Information Processing System (SIPS) battery (Wass et al., 2008). The child was asked to listen to sentences with the last word missing. The child was then asked to fill in the missing word. After listening 

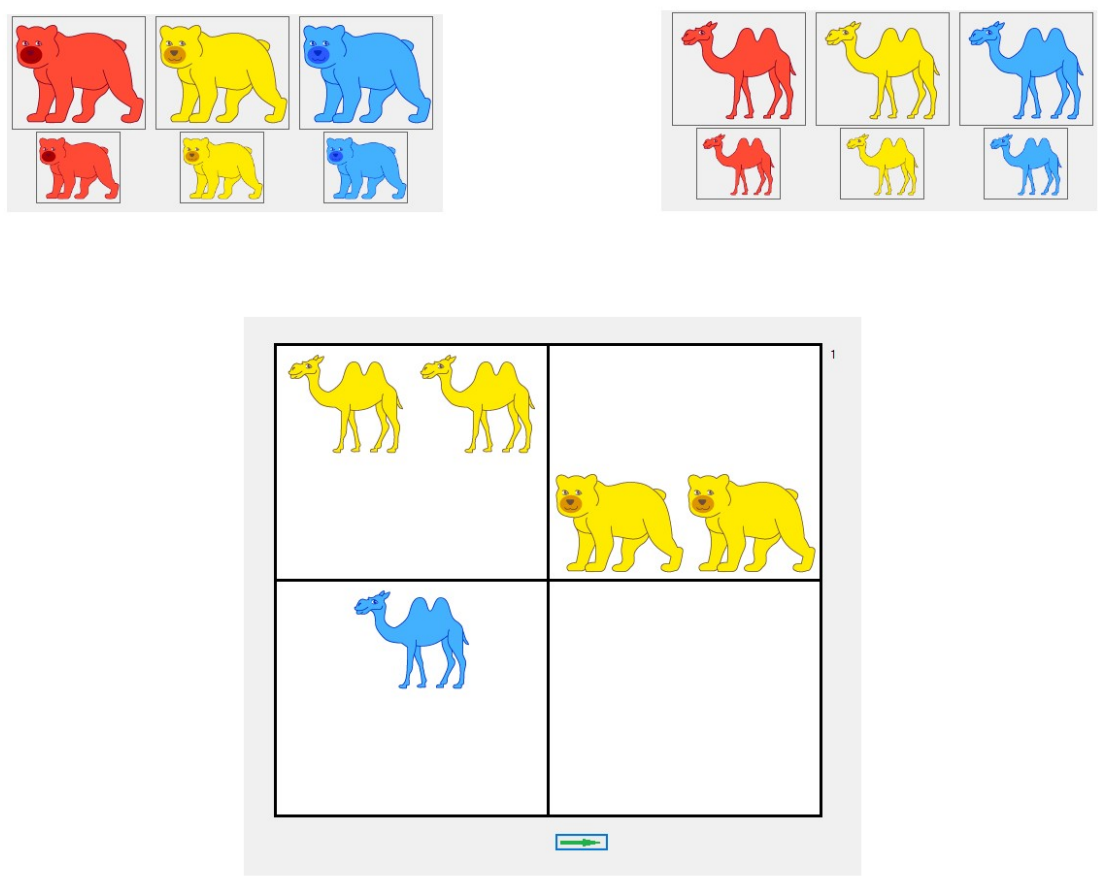

Figure 5: An example picture from Animalogica.

to a number of sentences, the child was asked to recall the last word of each sentence. The test consisted of two blocks, in each block the number of sentences increased from two to four. The child received one point for every correctly recalled word. The total number of trials was 18 and therefore the maximum possible score was 18 . The task took around 10-15 minutes.

\section{Non-verbal WM}

Non-verbal WM was assessed using the Visual Matrix Patterns test from the SIPS battery (Wass et al., 2008). The child saw a 5x5 matrix of 25 grey blocks on the computer screen. A pattern of blocks turned black. The child was asked to recall the pattern by clicking on the blocks. The difficulty level ranged from one to eight blocks. Each level consisted of three different patterns. The task was terminated if the child was not able to recall two of the three patterns for 
the last two levels. The child got a point for every level in which they recalled at least two of the three patterns correctly. The total number of trials was 24 and the maximum score was 8 . The task took around 5-10 minutes.

\section{Language Tests}

For the current thesis, language comprehension ability, story comprehension ability, expressive vocabulary, expressive grammar and pragmatic language ability were accessed. The language tests used in the current thesis are listed in Table 3.

\section{Language Comprehension}

Language comprehension ability (referred to as receptive grammar in study IV) was assessed with the Test for Reception of Grammar 2 (TROG-2) test (D. Bishop, 2009). The child listened to recorded sentences, spoken by a female native speaker, and had to choose which of four pictures corresponded to the sentence. The child was asked to point at the correct picture. The test consisted of 20 blocks, which each consisted of four sentences. The test was terminated if the child gave the wrong answer to one or more sentences in four consecutive blocks. The maximum score was 20 and the task took around 20 minutes.

\section{Story Comprehension}

A Swedish translation (Eldblom \& Sandberg, 2011; Holck et al., 2009) of a story comprehension task developed by D. V. Bishop and Adams (1992) was used to evaluate the story comprehension ability of the children. Two stories were available in Swedish (Eldblom \& Sandberg, 2011). One consisted of six sentences, the other of seven sentences. The child listened to the story and was subsequently asked 14 question, seven inferential and seven literal questions.

\section{Expressive Vocabulary}

The Expressive Vocabulary task from the Clinical Evaluation of Language Fundamentals 4 screening test (CELF-IV) battery (Semel et al., 2004) was used. The child had to name pictures or parts of pictures. For each correct answer, the child received one point. The test was terminated if the child gave the wrong answer to four consecutive trials. The total number of trials was 18 and therefore, the maximum possible score was 18 . The task took around 5-10 minutes.

\section{Expressive grammar}

Expressive grammar ability was measured with the Formulated Sentences task from the CELF-IV battery (Semel et al., 2004). The child saw a picture and 
was asked to describe it using a target word. The child received between zero and two points for their answers, depending on whether they used the target word, described the picture, used a full sentence, or made any grammatical mistake. The test was terminated if the child got 0 points for four consecutive sentences. The total number of trials was 22 and the maximum possible score was 44 . The test took around 15 minutes.

\section{Pragmatic Language Ability}

The Pragmatics Profile from the CELF-IV battery (Semel et al., 2004) was used. Parents filled in the questionnaire for their child. They were asked to judge statements about the pragmatic skills of their child using the categories: Never, Sometimes, Often, Always. When scoring, never was counted as zero points, sometimes as one, often as two and always as three. For the sum score, the rating of all statements in the questionnaire was summed up. The maximum score was 150 . For the sub-measures: Rituals and Conversational Skills - RCS (e.g., makes/responds to greetings to/from others), Asking for, Giving and Responding to Information - AGRI (e.g., asks for help from others appropriately), and Non-Verbal Communication — NCS (e.g., knows how someone is feeling based on non-verbal cues) the items were summed up as described in Pearson Education (2008a) and Pearson Education (2008b). The maximum score for RCS was 66 , for AGRI it was 51 , and for NCS it was 39.

\section{Cognitive Training}

The computerized reasoning training by Lenhard et al. (2011) was translated from German to Swedish for the current thesis. The developers of the "Denkspiele mit Elfe und Mathis" [Thinkgames with Elfe and Mathis] (Lenhard et al., 2011) provided the author of the current thesis with an editable version of the training. It included all the descriptions and dialogues used in the game. This material was translated to Swedish by a teaching student proficient in both German and Swedish. The material was subsequently reviewed by two Swedish native speakers and the language was adapted to be suitable for children aged 6 (using easier terms and clear grammatical structures). The material was recorded, spoken by two female and one male native Swedish speaker.

The program by Lenhard et al. (2011) is based on the "Denkspiele" by Klauer (1989a), a reasoning training which has shown transfer effects both to reasoning measures (Klauer \& Phye, 2008) and to language measures (Marx, 2006). The differences between the original version and the version used in the current thesis are described in detail in paper IV. The computerized version was modernized in terms of items used (images of objects no longer part of the children's' life, e.g. a typewriter, were replaced) and answers with several 
possible answers were replaced with task with only one possible answer. In addition, an overarching story was added to achieve a game-like character in the training.

The children conducted the training on laptops, which were borrowed from the university. The whole training program consisted of 120 reasoning tasks. A task had to be solved correctly to move to the next task. All children in study II and III finished the training program. This means, they correctly solved all of the 120 tasks. For study II, the number of tries they needed to solve a task was used as one outcome measure. Of the 120 reasoning tasks, 20 were generalization tasks, 20 were discrimination tasks, 20 were cross-classification tasks, 20 were tasks in which relationships had to be recognized, 20 were task in which relationships had to be differentiated, and 20 were system construction tasks. For each category of task, there were introductory tasks with blocks, and more advanced tasks with pictures and symbols. The children played for six weeks, on five days a week and were asked to solve 6 tasks during each training session. In the unsupervised training group, the children received feedback and tips from the game characters. In the supervised training group, the children also received feedback and tips from the game characters and were in addition supposed to discuss their answers with their parents. The parents received a training protocol which they were asked to work through for every task in the game. The teachers in study III received the same protocol. The training protocol was translated from the manual of the German version of the training program by Lenhard et al. (2011) by the author of this thesis. The translation was checked by a native Swedish speaker. For a detailed description of the protocol, see study III. Both the teachers and parents received a manual on how to use the training program. In addition, the test leader was present for the first test session of the unsupervised training group and the group trained in study III. In addition, the test leader introduced each parent from the supervised training group to the training program.

\section{Procedure - Behavioural tests}

The children were all tested individually in a quiet room, either at home or at school. For the children with CIs and the children with TH, the test leader made sure that the auditory stimuli were heard by the child by asking if the sound level needed to be enhanced. All children except the children in the supervised training group from paper IV were tested by a speech and language pathologist or a speech and language pathologist student in the last university term. The test sessions were recorded and the children were allowed to take breaks whenever they asked for it. 


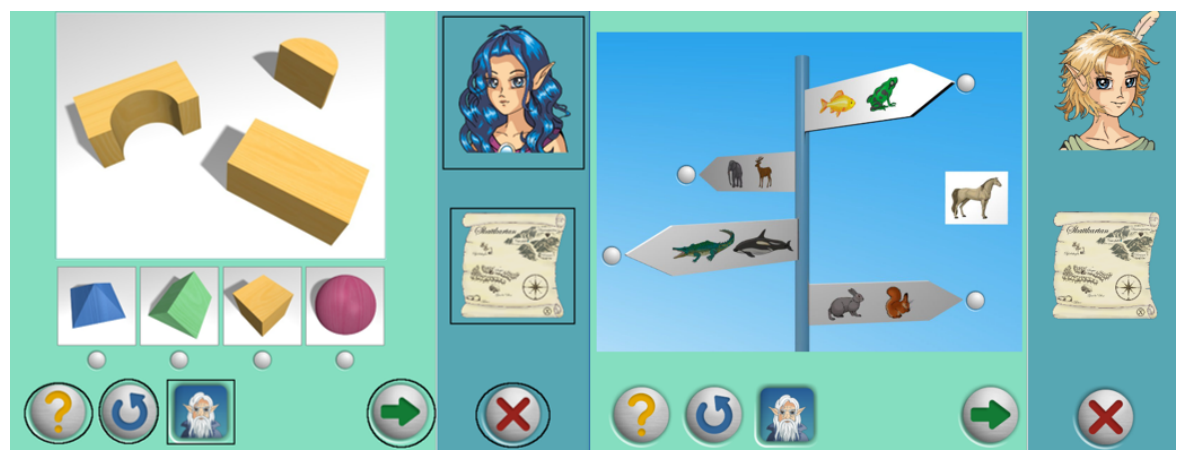

Figure 6: Two example tasks from the cognitive training program by Lenhard et al. (2011) used in the current thesis.

\section{Statistical analyses}

The statistical analysis in all four studies was conducted using the statistical software R and R Studio ( $\mathrm{R}$ Core Team, 2016). The packages used in the studies are listed in the respective paper. In each paper a detailed description of the statistical analysis can be found under "Statistical Analysis".

\subsection{Methodological Challenges}

\section{Research on children with CIs}

It is a challenge to recruit children for research, especially in a country with a small population. It is even more of a challenge to recruit children with CIs, who are a small population. In addition, heterogeneity is a problem when studying children with CIs, and finding a uniform group is nearly impossible. The children with CIs tested in the current thesis are no exception. They differed in terms of age at implantation, age at detection of deafness, reasons for deafness, schooling, and whether they used sign support, only oral language, or both sign- and oral language (see Table 2). All these factors possibly influence language development (Boons et al., 2013; Geers \& Nicholas, 2013; Thagard et al., 2011). In addition, no information concerning the hearing threshold before implantation or the socio economic background of the children were collected. These are also factors which have been found to influence language development (Geers \& Nicholas, 2013; Geers \& Sedey, 2011).

The sample size for the children with CIs was small and the group was heterogeneous. A small sample size leads to a reduction of power, which increases the likelihood of a type II error and an inflation of the effect size (Colquhoun, 2014). For this reason, the individual data, as well as the data on group level, is presented graphically in all studies in addition to the statistical tests to make it easier for the reader to judge the reliability of the statistical result. 
However, due to the small sample, the results from this thesis should be interpreted with caution, and replications are needed to confirm the patterns seen in the studies.

\section{Measurements}

The impurity of measurements is an issue both for testing cognition and for testing language ability. Performance can rely on a variety of abilities. Importantly, the performance on cognitive tests can be influenced by language ability as the performance on language tests can be influenced by cognitive ability. This needs to be taken into consideration when comparing groups of children. To address this issue, the children in Study I were matched on nonverbal analogical reasoning and WM before being compared in terms of their expressive language. In Study IV, two of the three groups were matched in terms of language, while the third one was not. This allowed for the evaluation of whether differences in verbal and non-verbal analogical reasoning are only observed in groups differing in language ability. However, language ability was only measured with a receptive grammar task and the influence of other language abilities, like expressive vocabulary was therefore not controlled for. This might have influenced the results. In Studies II and V participants were not matched on any language or cognitive variable. In Study V in particular it is possible that the differences in the observed association patterns are due to differences in language ability (grammar \& vocabulary).

Apart from the impurity problem, a critique in relation to the measures could be the usage of a questionnaire to assess pragmatic language ability. Although such a measure makes it possible to get a broad estimate of the children's pragmatic language skills, it lacks objectivity. Optimally, both a subjective and objective measure (e.g. a referential communication task) should have been included. However, as children cannot be tested for too long a time, this was not possible in the current thesis. For further studies both a subjective and an objective pragmatic language measure should be considered.

\section{Cognitive Training}

In Studies II and III of this thesis, a cognitive training program (Lenhard et al., 2011) was used. The program was played by the children on a computer, either at school or at home with their caregivers. In both cases, the test leader was not present during the training sessions, and the test sessions were not recorded. Therefore, there was no control mechanism to ensure that the training was conducted in the correct way. For example, it was impossible to know if the parents provided too much help during the training. Originally, it was planned to analyse log-data to compare how much time the children spent with the program for each session. Although all children solved all 120 tasks it was not possible to analyse how much time the children invested in 
solving the tasks. This was due to technical issues which led to missing log data.

A second methodological consideration for Studies II and III is that one might argue that there was no far transfer to language as six weeks was not sufficient time for the transfer effects to occur. It is of course true that six weeks is a short time, and improvements in language caused by improved cognition might not be observable immediately. However, as the training did not lead to any improvements in analogical reasoning, far transfer to language caused by improved cognition is very unlikely even after a longer time period.

An additional limitation of Study II was that the children in the supervised training group were, unlike the other children, not tested by a speech and language pathologist, but by the author of this thesis. It could be argued that as the other test leaders had more experience with testing children, this might have led to an underestimation of the performance of the supervised training groups. However, as standard instructions and a standard procedure was used for all tests, different test-leaders are unlikely to have a large influence on the test results.

\subsection{Summary of the papers}

\section{Paper I}

Aim: This study aimed to evaluate if differences between children with CIs and children with TH in terms of expressive spoken language ability are due to differences in non-verbal analogical reasoning ability or WM.

Method: Children with CIs were compared to peers with TH on both expressive spoken vocabulary and expressive spoken grammar. The groups were matched on non-verbal analogical reasoning, verbal and non-verbal WM. The groups were also matched on mean age. However, due to the differences in age variance scaled scores have been used for the expressive spoken language measures.

Results: The children with CIs were found to perform significantly more poorly than the children with $\mathrm{TH}$ on the expressive spoken vocabulary task. In addition, variability between the children was significantly larger for children with CIs than children with TH. For the expressive grammar task, children with CIs neither performed significantly more poorly than children with TH, nor did they show a significantly larger variability. However, the interquartile range was larger for the children with CIs, indicating a greater spread of the middle $50 \%$ of the data.

Conclusion: The results indicate that individual differences in terms of expressive spoken language are larger in children with CIs and children with $\mathrm{TH}$, even when the groups are matched on non-verbal analogical reasoning and WM. This larger spread might be due to a greater importance of individual differences in cognitive ability for the expressive spoken language ability 
of children with CIs, or to additional individual variation, like the time of language deprivation, only present in the group of children with CIs.

\section{Paper II}

Aim: The aim of this study was to evaluate if a computerized analogical reasoning training leads to improvements in analogical reasoning ability if the training is used by the child alone or under the supervision of a parent. A second aim was to evaluate if the analogical reasoning training has far transfer effects on language ability.

Method: Only children with TH participated in the study. The supervised and unsupervised training group were compared to a passive control group. A mixed ANOVA was used to investigate whether the training increased the improvement between pre- and post-test. Three analogical reasoning measures were used: non-verbal analogical reasoning, non-verbal analogical reasoning (high relational integration demand) and verbal analogical reasoning. In addition, semantic fluency, phonologic fluency, and language comprehension ability were measured at both pre- and post-test. To investigate differences between the unsupervised and the supervised training group, group differences in the number of tries needed to solve the tasks within the training were evaluated.

Result: It was found that children training together with their parents (supervised) needed fewer attempts to solve the tasks in the training than children training alone (unsupervised). However, neither they nor the children training alone improved significantly more than the passive control group on the analogical reasoning measures. In addition, no far transfer effect to language skills was observed. However, a small positive association between the improvement in non-verbal analogical reasoning and verbal fluency was found.

Conclusion: The results from this study indicate that the computerized analogical reasoning training does neither lead to near transfer to analogical reasoning nor to far transfer to language ability when being used by the child alone or under the supervision of a parent. This might be due to a lack of meta-cognitive (strategy) training. The results suggest that improvements in non-verbal analogical reasoning lead to improvements in semantic fluency. It is, however, unclear if this is due to improved ability to build semantic categories or to improved test performance, as similar strategies might be of advantage for the non-verbal analogical reasoning and the semantic fluency task.

\section{Paper III}

Aim: This study aimed to evaluate if a computerized analogical reasoning training might lead to near transfer effects to analogical reasoning and far transfer effects to language ability for children with CIs. The aim was to in- 
vestigate the potential usefulness of a larger scale study of the program with this pilot study.

Method: This was a pilot study with only seven participants. All were children with CIs. The children used the computerized analogical reasoning training in groups of three to four together with a teacher. The group training and supervision by the teacher were incorporated to improve the strategy (meta-cognitive) training part of the training program. The groups consisted of children with CIs and children with HA, but as only the children with CIs participated in the baseline, pre-test, and post-test, only their data has been analysed for this study. Non-verbal analogical reasoning, non-verbal analogical reasoning (HRI) and verbal analogical reasoning were used as near transfer measures. Story comprehension, semantic and phonological fluency were used as far transfer measures. Due to the small sample, the analysis was based on visual investigation of the data.

Result: The visual investigation of the data showed that only one child improved more between pre-test and post-test compared to baseline and pretest on both non-verbal analogical reasoning tasks. No child improved more on both non-verbal analogical reasoning measures and the verbal analogical reasoning measure due to the training. The child that improved on both nonverbal analogical reasoning measures during the training period compared to between baseline and pre-test, did not improve more than the other children on the language measures. None of the children improved more between pretest and post-test compared to baseline and pre-test on story comprehension and the verbal fluency measures. For both semantic and phonological fluency, one child improved more between pre-test and post-test compared to baseline and pre-test. However, the performance of these two children decreased between baseline and pre-test and increased again between pre-test and post-test. Although an association between the improvement of nonverbal analogical reasoning and verbal fluency was found in Paper II, the visual investigation of the data in Paper III did not indicate that those children who improved more on non-verbal analogical reasoning between baseline and post-test improved more in their semantic verbal fluency ability between baseline and post-test compared to the other children.

Conclusion: The result pattern found in this study does not indicate that this computerized analogical reasoning training is a promising way to improve the analogical reasoning and verbal fluency ability of children with CIs.

\section{Paper IV}

Aim: This study had two aims. The first aim was to investigate the relationship between analogical reasoning and language ability in children with CIs and children with TH. The second aim was to evaluate the analogical reasoning abilities of children with CIs.

Method: Children with CIs, and two groups of children with TH were com- 
pared with each other. One group of children with TH was matched with the children with CIs in terms of receptive spoken grammar and age, the other groups was only matched in terms of age. All three groups were tested on non-verbal analogical reasoning ability and verbal analogical reasoning ability. To test non-verbal analogical reasoning ability, two tests which differed in complexity were used. One of the tests had a multiple choice answering format, and the first trials could be solved by simple pattern matching. The other test had an open answer format and relational integration had to be used from the first trial.

Result: The children with $\mathrm{TH}$ and higher receptive spoken grammar ability were found to perform significantly better than the children with $\mathrm{TH}$ and lower receptive spoken grammar ability on all three analogical reasoning tasks. The children with CIs were found to perform significantly more poorly on the more complex reasoning measure (i.e. that included a higher relational integration demand) compared to children with $\mathrm{TH}$ and higher receptive spoken grammar ability, but performed at the same level as children with TH matched for receptive spoken grammar. For the less complex non-verbal analogical reasoning measure, there was only a tendency towards a significant difference between the children with CIs and the children with $\mathrm{TH}$ and higher receptive spoken grammar ability. The children with CIs also performed at the same level as children with TH matched for receptive spoken grammar on this task. For the verbal analogical reasoning task, children with CIs performed significantly poorer than both groups of children with TH.

Conclusion: The results suggest that higher language ability boosts the performance for complex non-verbal analogical reasoning tasks (those that including higher relational integration demand). However, non-verbal and verbal analogical reasoning also seem to be important for language comprehension ability. It could be that analogical reasoning includes two sub-abilities: pattern matching and relational integration. The first might be important for language acquisition and the latter might be boosted by higher language ability. To examine this further, more studies are needed in which patternmatching and relational integration ability are measured separately from each other. Performance on a verbal analogical reasoning task might be influenced more by expressive vocabulary than by receptive grammar skills. This might explain for the differences in performance between children with CIs and children with TH matched on receptive spoken grammar skills.

\section{Paper V}

Aim: The first aim of this study was to compare the pragmatic language ability of children with CIs and children with TH. The second aim was to investigate if core language measures and verbal cognitive skills are associated to the pragmatic language ability of the two groups.

Method: Children with CIs were compared to children with $\mathrm{TH}$ in terms 
of their pragmatic language skills. The pragmatics profile questionnaire from the CELF-IV battery was filled in by the children's caregivers, and the sum value as well as the value for three sub-measures, Rituals and Conversational skills (RCS), Asking for, Giving, and Responding to Information (AGRI) and Non-verbal Communication skills (NCS), were compared between the groups. In addition, associations between the three sub-measures of pragmatic ability and core language skills (language comprehension, vocabulary) as well as verbal cognitive skills (verbal fluency, verbal WM, and verbal analogical reasoning) were evaluated for both the children with CIs and the children with TH.

Result: For the sum score of the pragmatics profile, no significant difference was found between the children with CIs and the children with TH. However, 5 out of 14 children with CIs performed below age norm, while only 2 out of 34 children with $\mathrm{TH}$ performed below age-norm. All children with CIs performing below age-norm were attending special school, while those performing above age-norm were both children attending special school and children in mainstream education. A tendency for a significant difference was found for the RCS measure and a significant difference was found for the NCS measure. All three sub-measures of pragmatic ability were correlated to verbal fluency for the children with CIs, but not for the children with TH. For the children with TH, verbal analogical reasoning and receptive grammar ability was positively associated with the RCS measure. In addition, vocabulary skills and verbal analogical reasoning ability were positively correlated to the NCS scale for children with $\mathrm{TH}$.

Conclusion: The results from this study indicate that many children with CIs show comparable pragmatic language skills to peers with TH. However, as all children performing below age-norm attended special school, more research is needed on the influence of different educational environments on the development of pragmatic language ability. In addition, verbal fluency was found to be associated with pragmatic language ability of children with CIs. This was not the case for children with TH. It might be the case, that children with a better developed semantic network perform better on a verbal fluency task and are also better able to use language in a flexible way. Children with TH might already have a more developed semantic network and further improvements might not influence their pragmatic language ability. 


\section{Discussion}

\subsection{Summary of the results}

The aim of the current thesis was to investigate the language and analogical reasoning ability of children with CIs in comparison to children with TH. In addition, the aim was to analyse the association between those two skills. Differences between children with CIs and children with $\mathrm{TH}$ in all tested domains, as well as a reciprocal relationship between analogical reasoning and language ability were expected (see Figure 2).

A larger variance in expressive language was found in children with CIs compared to children with TH matched on non-verbal analogical reasoning ability and WM (Study I). This suggests either a greater importance of cognitive skills for the language development of children with CIs or the importance of individual variation only present in the group of children with CIs, like the age at implantation.

The analogical reasoning training used in the current thesis (Lenhard et al., 2011) did not show any effects on analogical reasoning or language ability. This was the case both for children with TH (Study II) and children with CIs (Study III). However, a small association between improvements in non-verbal analogical reasoning and semantic verbal fluency was found in Study II. This association might be explained by improved abilities to use strategies needed both for analogical reasoning and semantic verbal fluency tasks.

The results of Study IV indicate that complex non-verbal analogical reasoning and verbal analogical reasoning are supported by language. For complex non-verbal analogical reasoning this might be due to the use of verbal strategies. In Study IV the children with CIs were found to perform more poorly on a verbal analogical reasoning task than children with TH matched for language comprehension skills, despite having comparable non-verbal analogical reasoning ability. Verbal analogical reasoning ability seems to be not only influenced by receptive grammar skills, but might be more dependent on expressive vocabulary and lexical access ability.

In Study V it was found that all children with CIs who showed a delay in pragmatic language ability attended special schools . However, this data might be explained by the fact that children with a more prevalent language delay are more likely to be educated in a special school. Verbal fluency was the only verbal cognitive measures associated with pragmatic language ability for the children with CIs, while vocabulary, grammar, and verbal analogical reasoning ability were associated with pragmatic language ability for children with 


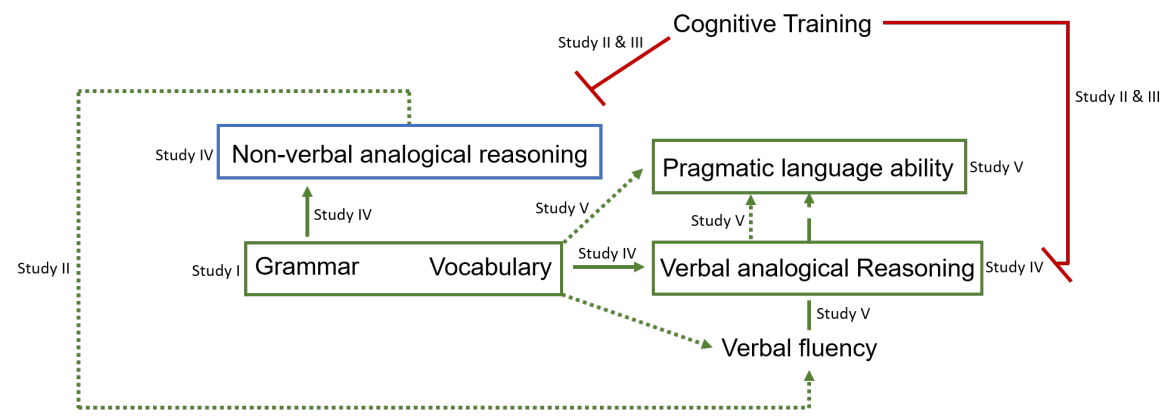

Figure 7: A graphical representation of the results of the current thesis. A green arrow is used for observed patterns. A dotted (...) arrow is used for patterns which were only found for children with TH, while a dashed (- - -) arrow is used for results which were only found for children with CIs. Red is used for null results. A green box is used for abilities for which differences between children with CIs and children with $\mathrm{TH}$ were observed. A blue box is used for differences between children with CIs and children with TH that were only been observed when the groups differed in language ability.

TH.

The main results from the current thesis are presented in Figure 7 .

\subsection{Language and Analogical Reasoning: A reciprocal relationship?}

The pattern of results observed in this thesis indicates a reciprocal relationship between language and analogical reasoning ability. This is in accordance with Gentner and Christie (2010), who argue that analogical reasoning is of importance for language acquisition, but that language also serves as a boost for analogical reasoning skills. Improvements in analogical reasoning, however, seem to have a limited effect on language ability in the tested age-group. This is in contrast to studies with younger children, for which an improvement in analogical reasoning ability led to transfer effects to the language domain (Marx, 2006; Marx et al., 2010). The supporting role of language for analogical reasoning seems to play an important role for the age-group tested in this thesis. This is in accordance with studies showing that language ability is associated with complex non-verbal reasoning ability (Baldo et al., 2010; Baldo et al., 2015; Cejas et al., 2018).

\section{Analogical reasoning training}

If language acquisition relies on analogical reasoning ability, as suggested by Gentner and Namy (2006) and the usage-based model of language acquisition 
(Behrens, 2009; Tomasello, 2009), then an improvement of analogical reasoning ability should boost language acquisition. This boost would be expected for grammar ability, as well as for the ability to build semantic categories, as both these skills have been found to be associated to analogical reasoning ability in previous studies (Childers et al., 2016b; Childers \& Tomasello, 2001; Gentner \& Namy, 1999; Gerken, 2010). However, in this thesis it was not possible to improve analogical reasoning ability with a computerized cognitive training.

In Study II the computerized analogical reasoning training by Lenhard et al. (2011) was used in a way that would make it suitable for children with CIs. Children with CIs are a small population and spread all over the country which makes a cognitive intervention hard to conduct if it has to take place at a clinic. If children can take part in a training without having to travel then this would make the training feasible for a larger group of children. In addition, a training that can be used at home without a professional supervisor is not only easier, but also cheaper to conduct. This can be an important factor for families when they decide which interventions their child can take part in. Previous research has shown that at-home interventions can be effective for children with CIs (von Mentzer et al., 2013).

The aim of Study II was to investigate, if the computerized analogical reasoning training by Lenhard et al. (2011) improves the analogical reasoning skills of children, whether they train alone or under the supervision of a parent. The results show that neither method of training led to any effect. It could be argued that the level of metacognitive training was too low in these two training alternatives. Klauer (1996) argues that the metacognitive aspect of an analogical reasoning training is of importance to ensure effects. Metacognition refers to the ability to reflect on one's own thinking processes. If the children learn how they solved a specific analogical reasoning problem and are able to reflect on the cognitive strategies they used, they might be better able to use these strategies again for similar problems. Therefore, the parents were among other things instructed to discuss the answers with the child and to let the child explain their reasoning behind their answer (see paper II \& Method section for a detailed list). The aim of this was that the child develops strategies to solve analogical reasoning tasks. However, the results from Study II show that the training had no effect despite this. It might be the case that the parents offered too much help and the children were therefore not able to come up with their own strategies. One indication for this is that children training with their parents had a lower error rate within the training compared to children training alone.

In Study III the training was conducted as a group training with children with CIs under the supervision of a teacher. A teacher is a more professional supervisor than a parent. This might reduce the risk of the adult supervisor providing too much help. In addition, due to the group training the children had to explain their answers to other children who might be more critical 
that an adult supervisor. Both these aspects were intended to increase the effectiveness of the metacognitive aspect of the training. However, the pilot results obtained in Study III do not indicate that the computerized analogical reasoning training (Lenhard et al., 2011) would increase analogical reasoning or language ability in children with CIs. This is in accordance with claims by Roth-van der Werf et al. (2002) who found that the analogical reasoning training developed by Klauer $(1989 \mathrm{~b})$, on which the computerized version used in the current thesis (Lenhard et al., 2011) is built on, does not lead to any transfer effects.

A small association between improvements in non-verbal analogical reasoning and verbal fluency ability has been found in Study II. This is in accordance with the importance of analogical reasoning ability for the building of semantic categories (Gentner \& Namy, 1999). No associations between improvement in analogical reasoning and receptive grammar ability was found. The results for the semantic fluency task could both be explained by an improved ability in building semantic categories, but also by improved abilities to use strategies both needed for analogical reasoning and semantic verbal fluency tasks. The small size of the association indicates that large improvements in semantic fluency would not be expected by increased analogical reasoning ability. The results from Study III do not indicate that those children with CIs who improved more on non-verbal analogical reasoning between baseline and pretest improved more in their semantic verbal fluency ability between pre-test and post-test compared to the other children. This suggests that improved non-verbal analogical reasoning has no boosting effect on the development of semantic categories for children with CIs. The results from Study III are from a small sample. However, they indicate that a larger scale study with children with CIs using an analogical reasoning training program is unlikely to lead to transfer effects on language ability.

\section{The influence of language ability on analogical reasoning}

The results from the current thesis show that differences between children with CIs and children with TH in complex analogical reasoning are absent if the groups are matched on language comprehension ability. However, children with CIs were found to performed significantly more poorly on a verbal analogical reasoning task compared to children with TH matched on language comprehension and non-verbal analogical reasoning ability. The reason for this could be that a language comprehension measure was used for the matching, while the verbal analogical reasoning task required expressive vocabulary skills. In addition, differences might be explained by differences in the structure of the mental lexicon.

Language ability has been found to improve analogical reasoning (Baldo et al., 2010; Baldo et al., 2015; Cejas et al., 2018). This in accordance with previous research, finding that language ability is the most important predictor 
for the non-verbal analogical reasoning ability of both children with CIs and children with TH (Cejas et al., 2018). In addition, it has been found that verbal analogical reasoning ability is strongly associated with language ability (Edwards et al., 2011) and differences found between children with CIs and children with $\mathrm{TH}$ on this task might therefore be explained by differences in language ability.

\section{Non-verbal analogical reasoning}

The results from this thesis indicate that language abilities influence the performance on non-verbal analogical reasoning tasks. Study IV is the first study to compare children with CIs to both language and age matched peers on non-verbal analogical reasoning tasks with high and low relational integration demands. Children with CIs perform comparably to language and age matched peers on both those tasks. However, they perform significantly more poorly than age matched children with $\mathrm{TH}$ with higher language ability on the non-verbal analogical reasoning task with higher relational integration demands.

A reason for the importance of language for analogical reasoning might be that relational integration is facilitated by the use of verbal strategies. Gentner (2016) argues that language can be used as a symbolic system to represent relational patterns. If relations can be verbalized in mind this might reduce the cognitive demands and thereby increase relational integration ability. This explanation is in accordance with a study by Baldo et al. (2010), who found that language ability is important for complex analogical reasoning but not for tasks that can be solved by simple pattern matching.

The non-verbal analogical reasoning tasks used in Study IV did not only differ in terms of relational integration demands but also in terms of the stimuli used. In the task with higher relational integration demand, animals changing position and color were used as stimuli, while abstract patterns were used for the other non-verbal analogical reasoning task. It could be argued that the tasks therefore differ in the amount to which verbal labelling can be used and the results found in Study IV are in accordance with results by Davidson et al. (2019). While verbal labelling might have facilitated the ability to use verbal strategies, it needs to be noted that even for the more abstract analogical reasoning task a tendency for a lower performance of children with CIs compared to children with TH and higher language ability was found. This indicates that verbal abilities might influence the performance. This is in accordance with results by Cejas et al. (2018), who found that language ability is an important predictor for the performance on an abstract analogical reasoning task. Further studies are needed to investigate the importance of verbal strategies for relational integration. These studies should use non-verbal analogical reasoning task which differ only in their relational integration demand, not in the abstractedness of the stimuli. 
Non-verbal analogical reasoning tests are often used in intelligence testing and have been claimed to be "language free" (non-verbal). However, if relational integration ability is influenced by language ability, these tasks might underestimate the non-verbal cognitive ability of children with language delays, as the more complex trials (with high relational integration demand) might be supported by language. This means, that a child with lower language ability might score lower on the more complex trials compared to a child with higher language ability even if both these children have comparable non-verbal cognitive ability. This is in accordance with results from Dugbartey et al. (1999) who found associations between verbal skills and performance on the Matrix task (a non-verbal analogical reasoning task) from the WNV battery (Wechsler \& Naglieri, 2007). Dugbartey et al. (1999) suggested that the task is not fully non-verbal and is mediated by verbal ability. This raises the question of whether non-verbal analogical reasoning tasks are an appropriate measure for the non-verbal intelligence of children with CIs.

\section{Verbal analogical reasoning}

In Study IV, children with CIs performed significantly more poorly on a verbal analogical reasoning task compared to children with TH matched on language and non-verbal analogical reasoning ability. This indicates that the lower performance of children with CIs on this task can not be explained by a language delay. This was a surprising result. It was assumed that children with the same language level should have comparable verbal analogical reasoning ability. Masterson et al. (1993) for example found that children with language learning disabilities performed comparably to language-matched children on a verbal analogical reasoning task. However, for Study IV receptive grammar was used as a language measure, while Masterson et al. (1993) used vocabulary as a language measure. It might be the case that the children with CIs and the children with TH were matched on language comprehension ability, but not on other language abilities which are important for verbal analogical reasoning, such as lexical access. The verbal analogical reasoning task used in Study IV is an expressive task, in which a missing word has to be filled in. Therefore, lexical access is important. Lexical access ability can differ due to differences in vocabulary size or due to differences in the structure of the mental lexicon. Vocabulary has been found to be an important predictor for the verbal analogical reasoning ability of children with CIs in previous studies (Edwards et al., 2011). In Study IV, differences in the expressive vocabulary of the children with CIs and the children with TH could not be evaluated due to missing data. However, in Study I, the children with CIs have been found to perform significantly more poorly on an expressive vocabulary task compared to children with TH matched for non-verbal analogical reasoning ability. It therefore is likely that differences in vocabulary size are one explanation for the differences in verbal analogical reasoning between children with CIs and 
children with TH found in Study IV. The groups might have additionally differed in terms of the structure of their mental lexicon. A study by Kenett et al. (2013) shows that the mental lexicon of children with CIs is less connected compared to the mental lexicon of peers with TH. In a less connected mental lexicon, related words might not be automatically activated. This might make a verbal analogical reasoning task more demanding for children with CIs.

\section{Pragmatic Language Ability}

An association between pragmatic language ability and verbal analogical reasoning was found for the children with TH. This is in accordance with research by Loukusa et al. (2007). In Study V, associations were found for rituals and conversational skills, as well as for non-verbal communication skills. The majority of the items used to measure rituals and conversational skills were related to turn-taking ability. The found association with verbal analogical reasoning might therefore be explained by the use of verbal analogical reasoning to make predictions about the meaning of an utterance during conversation (Levinson, 2016). The association between verbal analogical reasoning and non-verbal communication skills is in accordance with the Relevance Theory (Sperber \& Wilson, 2004). Non-verbal gestures, facial expressions and intonation need to be integrated with the literal meaning of an utterance to draw inferences about the true meaning. It is expected that children with higher verbal analogical reasoning ability would be better able to draw these inferences. However, as only correlations have been calculated, the causality of the found associations is currently unclear.

The association between verbal analogical reasoning and pragmatic language ability was non-significant for the children with CIs. Verbal fluency was instead found to be significantly associated with pragmatic ability for the children with CIs. This was the case for rituals and conversational skills, as well as for non-verbal communication skills. Kenett et al. (2013) argue that semantic fluency is a measure of the connectivity of the mental lexicon. It could be speculated that the reason for the result of Study V is that children with CIs with better structured mental lexicon are not only able to produce more words during a verbal fluency task as their lexical access ability is higher, but they might also be able to use language in a more flexible way. This is important for social communication as the used language needs to be adapted to the listener and the situation.

The different pattern found for children with CIs and children with TH in Study V might be explained by a mediation effect. A less structured mental lexicon might influence lexical access, which influences verbal analogical reasoning, which influences pragmatic language ability. For the children with $\mathrm{TH}$, who tend to have a more structured mental lexicon than peers with CIs, the verbal fluency ability might no longer fully mediate the association between verbal analogical reasoning and pragmatic language ability. This might 
explain why the same sub-abilities have been associated to verbal analogical reasoning for children with $\mathrm{TH}$ as have been associated to verbal fluency for the children with CIs. Further studies are needed to evaluate if analogical reasoning ability is associated with pragmatic language skills in both children with $\mathrm{TH}$ and children with CIs if the groups are matched on verbal fluency ability.

\section{Summary}

- Differences in expressive language between children with CIs and children with TH are not explained by differences in non-verbal analogical reasoning ability or differences in working memory (Study I). Children with CIs perform more poorly on an expressive vocabulary task and show a larger variation in both expressive vocabulary and expressive grammar compared to children with TH matched on non-verbal analogical reasoning and working memory.

- The results from Study II and IV support the hypothesis that language ability and analogical reasoning have a reciprocal relationship. Language ability has been found to be of importance for complex non-verbal analogical reasoning, as well as for verbal analogical reasoning ability. On the other hand, indications have been found that analogical reasoning ability might influence the language ability of children with TH and improvements in non-verbal analogical reasoning have been found to be associated to improvements in semantic fluency for children with $\mathrm{TH}$ (Study II).

- The results from Study IV support the hypothesis that language delays lead to differences between children with CIs and children with $\mathrm{TH}$ on cognitive tasks. This was the case both for a verbal task and a task that benefits from verbal strategies.

- The results of Study IV and Study V indicate that vocabulary and the structure of the mental lexicon are influencing higher order language skills such as verbal analogical reasoning and pragmatic language ability of children with CIs.

\subsection{Conclusion}

The results from the current thesis show that the language delays often seen in children with CIs are not explained by delays in cognitive abilities. Rather, the language delays affect the performance on cognitive tasks which are either verbal or can be supported by verbal strategies. In the tested age-group, the influence of an improvement of analogical reasoning on language ability is limited. The influence of language ability on analogical reasoning seems to 
be more relevant. The results of this thesis indicate that vocabulary and the structure of the mental lexicon, influence the performance on higher-order language skills such as verbal analogical reasoning and pragmatic language ability. Both the size of the vocabulary and the structure of the mental lexicon are likely influenced by the amount of language input a child receives. The main implication of this is that emphasis should be put on reducing the duration of language deprivation and to improve the quality of the language input for children with CIs.

\subsection{Future Directions}

The results from this thesis and previous studies show that language delays affect not only communication ability, but also the performance on cognitive tasks. Future research should concentrate on how to reduce language delays in children with CIs. As usage-based models of language acquisition argue, language is learned by using it. Therefore, reducing the duration of language deprivation and improving the quality of the language input are likely the most promising approach. Future studies need to evaluate how this can be achieved in a good way for each individual child with CIs. The duration of language deprivation could be reduced by using sign-language or HAs before the child receives CIs. The use of sign-language or cued speech, as well as improved technology of CIs are ways to improve the input quality.

Future studies should focus on a more integrative evaluation of language ability. Little research has been done on how the combined use of spoken and sign language affects the language and cognitive development of children with CIs. For children with CIs with hearing parents, having CIs improves the input quality of the language as the parents are able to communicate in their native language. Using sign-language improves the input quality of the language as no information is lost due to reduced auditory quality. Therefore, it should be evaluated if a combined use of spoken language (with the parents) and sign language (with a tutor/in kindergarten) can lead to an optimal language environment for children with CIs.

The findings from Study IV and V indicate that the structure of the mental lexicon is important for higher-order language skills of children with CIs. However, only one study until now has investigated the structure of the mental lexicon of children with CIs (Kenett et al., 2013). In the study by Kenett et al. (2013), children with CIs were compared to age-matched children with $\mathrm{TH}$, therefore, it is unclear if the observed differences are due to differences in age at language acquisition. Further studies are needed to evaluate whether the mental lexicon of children with CIs is developed as would be expected from their language age, or if reduced input quality due to the CI leads to weaker connections between the words in the mental lexicon. If this is the case, this could have implications on verbal analogical reasoning ability and therefore 
on several higher-order language skills, like pragmatic language skills. Pragmatic language ability is an essential skill for the participation in communications. More research is needed to evaluate the pragmatic language ability of children with CIs and which factors are influencing it. Studies are needed which can untangle the influence of language delays and input quality on the turn taking ability of children with CIs. Turn taking might be influenced by the ability to hear auditory cues, but also by the ability to predict the meaning of an utterance. In addition, the reasons for the significant differences in non-verbal communication ability between children with CIs and children with TH, found in Study V, need to be evaluated more closely. These differences could be due to delays in ToM. However, they might as well be due to the fact that spoken language is more cognitively demanding for children with CIs. They might therefore not have enough cognitive resources left to integrate non-verbal information with the literal meaning of an utterance. In addition, some of the children might rely in parts on lip-reading and will therefore miss important facial cues.

Results from the current thesis as well as previous findings indicate that language ability is influencing the performance on non-verbal analogical reasoning tasks. More research is needed to evaluate why this is the case. The most likely explanation based on the current data is that relational integration is supported by verbal strategies. Even if the stimuli are abstract, relational language (e.g. directions or dimensional terms) might still improve the ability to verbalize relations in mind. This might reduce the working memory demand of the relation integration process and therefore make it possible to solve more complex analogical reasoning tasks. The matrices used in non-verbal intelligence measures need to be evaluated in terms of how well the relations can be verbalised. How well a participant is able to verbalise relations might even depend on their language, as languages differ in terms of which and how many relational terms are used. This needs to be taken into consideration when comparing the non-verbal analogical reasoning ability of children with different language backgrounds. In addition, the supporting role of language for relational integration ability needs to be taken into consideration when comparing the non-verbal analogical reasoning ability of groups of children which differ in terms of their language ability, for example children with CIs and children with TH. 


\section{Acknowledgments}

When I moved to Sweden almost 6 years ago, I could never have imagined how much I would learn and how much support, friendship and love I would experience. Doing a Ph.D. has been one of the hardest things I have ever done. I am deeply thankful for this experience almost as much as I am thankful that it is finally over!

First and foremost, I want to thank all the children who participated in the studies. Although most of you have been tested by somebody else, I very much enjoyed getting to know some of you! I also want to thank the parents and teachers who made the testing possible. I have meet so many nice and dedicated teachers and even learned something about the Swedish school system on the way.

I want to thank my main supervisor Björn Lyxell for making this project possible. Thank you for sharing your stories and your knowledge about the research world with me. I also want to thank my co-supervisor Malin Wass for all the support, feedback and warm words. I enjoyed sharing an office with you a lot, although it was only for a short time. I am also very thankful that my second co-supervisor, Rachel Ellis, agreed to join the project. Thank you for all the statistical advise and the pep talks. You have been a great help!

My Ph.D. project was part of the project iCARE and I would like to thank all the people that made this project possible. A special thanks to AnnCharlotte Gyllenram, Astrid van Wieringen, and Carsten Svensson for welcoming me for a secondment. A big thank you to all the great iCARE Ph.D. students and post docs: You have made this journey so much more fun!

There are several people who offered a lot of help in the initial phase of my Ph.D. I want to thank Mathias Hällgren for helping me with the recording and for playing Osarion, and Birgitta Sáhlen and Christina Samuelsson for feedback on the language tests. A big thanks to Helena and Johanna who have been the best Älvan and Mathis I could have wished for. It has been a pleasure recording the Swedish version of the Denkspiele with you! I want to thank Claire Stevenson for creating a Swedish version of the Animalogica test and Anna Wretman for being the speaker for this test. I also want to thank Alexandra Lenhard and Wolfgang Lenhard for helping me create a Swedish version of their program "Denkspiele". The children enjoyed your game very much! 
I want to thank Malin Gärskog, Ingrid Hedström and Lin Hellgren for help with the data collection. A thanks to Elias Ingebrand both for help with the data collection and for being such a fun company at the iCARE winterschool.

Thankfully, I did not have to work alone during my Ph.D. time. I want to thank all my colleagues at IBL for the nice talks during the fika and lunch breaks! A special thanks to: Carine Signoret, for welcoming me and for sharing your experience with Sweden and Swedish people; Josefine Andin, for all the discussions, your support and help and for never turning down a fika or in-between-fika-and-lunch break; Henrik Danielsson, for all the great summer schools and discussions. I also want to thank Maria Hugo-Lindén, Jonna Torstensson and Anette Larsson for helping me with the administrative work and for always taking the time to answer my questions.

A big thank you to all my great fellow (past and present) Ph.D. students and Post Docs at IBL! I am so happy that I got to know all of you. A special thanks to: Elisabeth Ingo, thank you for always listening to my rants and for being such a caring and wonderful friend. Thanks for being my "TROG speaker". Lisa Palmqvist, thank you for all of your support, time, kindness and friendship. Keep up the fake German! Rina Blomberg, thank you for always speaking your mind. Karin Nilsson, thank you for making coming to work so much more enjoyable and for all the talks and discussion at work and in "real life". I am a big fan of your dialect imitations!Andreea Micula, thank you for making the foundation course so much more fun. Sharam Moradi, thank you for being such a welcoming and friendly colleague. Denis Shirnin, thank you for your support, your positive attitude and all the fun lunch breaks and conferences! Negin Chehrehnegar, thank you for all the nice talks on-line and off-line.

A big thanks to Rosie and Sarah for the good times at the language class and all the diners and laughters we shared. A very special thanks to Noemi: Vielen Dank für deine Freundschaft! Danke, dass ich mich immer bei dir auskotzen darf und dafür, dass du einfach immer da bist. Du fehlst mir sehr!

Finally, I want to thank the most important people in my life, my family! Without you, none of this would ever have been possible! Thank you Friedi, for being the best big sister in the world! Ich vermisse immer noch die Zeit in der wir ein Zimmer geteilt haben und ich jeden Tag (und jede Nacht) mit dir reden konnte. Du weisst einfach immer was ich denke, auch wenn ich gar nichts sag. Aber du weisst ja: Unsere Gedanken verschmelzen bereits! Thank you, Mama and Papa, for supporting me no matter what I do. Danke für eure Liebe, eure Unterstützung und dafür, dass ihr immer an mich glaubt!

During this Ph.D. journey I had the privilege to become the mother of two wonderful children, Luisa and Marlene. I never knew how much love I could 
feel until I met you. Ich liebe euch beide von ganzem Herzen! Ihr seid mein Ein und Alles $\odot$

The last person I want to thank is my wonderful husband and best friend: Dominik. Durch alle Höhen und Tiefen, alle Triumphe und Selbstzweifel warst und bist du immer an meiner Seite. Ich bin unendlich dankbar, dass wir gemeinsam durch dieses Leben gehen! Ich liebe dich $\odot$ 



\section{Bibliography}

Akçakaya, H., Aslan, F., Doğan, M., \& Yücel, E. (2018). Relationships between reasoning, verbal working memory, and language in children with early cochlear implantation: A mediation effect. Ankara Üniversitesi Equitim Bilimleri Fakültesi Özel Equitim Derqisi, 19(3), 485-509. https://doi.org/10.21565/ozelegitimdergisi.365076

Akçakaya, H., Doğan, M., Gürkan, S., Koçak, Ö., \& Yücel, E. (2019). Early cochlear implantation: Verbal working memory, vocabulary, speech intelligibility and participant variables. Cochlear Implants International, 20(2), 62-73. https://doi.org/10.1080/14670100.2019.1565077

Aslan, F., \& Yücel, E. (2019). Auditory reasoning skills of cochlear implant users. The iournal of international advanced otology, 15(1), 70. https: //doi.org/10.5152/iao.2018.5400

Baddeley, A. D. (2012). Working memory: Theories, models, and controversies. Annual review of psychology, 63, 1-29. https://doi.org/10.1146/ annurev-psych-120710-100422

Baddeley, A. D., \& Hitch, G. J. (1994). Developments in the concept of working memory. Neuropsychology, 8(4), 485. https://doi.org/10.1037/ 0894-4105.8.4.485

Baldo, J. V., Bunge, S. A., Wilson, S. M., \& Dronkers, N. F. (2010). Is relational reasoning dependent on language? A voxel-based lesion svmptom mapping study. Brain and Language, 113(2), 59-64. https://doi. org/10.1016/j.bandl.2010.01.004

Baldo, J. V., Dronkers, N. F., Wilkins, D., Ludy, C., Raskin, P., \& Kim, J. (2005). Is problem solving dependent on language? Brain and language, 92(3), 240-250. https://doi.org/10.1016/j.bandl.2004.06.103

Baldo, J. V., Paulraj, S. R., Curran, B. C., \& Dronkers, N. F. (2015). Impaired reasoning and problem-solving in individuals with language impairment due to aphasia or language delav. Frontiers in Psychology, 6. https://doi.org/10.3389/fpsyg.2015.01523

Behrens, H. (2009). Usage-based and emergentist approaches to language acquisition. Linguistics, 47(2). https://doi.org/10.1515/LING.2009.014

Benton, A. L., deS, K., \& Sivan, A. B. (1978). Multilingual aphasia examination: Manual of instructions. PAR.

Bishop, D. (2009). Test for reception of grammar, version 2 (trog 2). swedish version. London, UK: Pearson Assessment.

Bishop, D. V., \& Adams, C. (1992). Comprehension problems in children with specific language impairment: Literal and inferential meaning. 
Journal of Speech, Lanquaqe, and Hearing Research, 35(1), 119-129. https://doi.org/10.1044/jshr.3501.119

Boons, T., De Raeve, L., Langereis, M., Peeraer, L., Wouters, J., \& van Wieringen, A. (2013). Expressive vocabulary, morphology, syntax and narrative skills in profoundly deaf children after early cochlear implantation. Research in Developmental Disabilities, 34(6), 2008-2022. https://doi.org/10.1016/j.ridd.2013.03.003

Cejas, I., Mitchell, C. M., Hoffman, M., \& Quittner, A. L. (2018). Comparisons of IQ in Children with and without Cochlear Implants: Longitudinal Findings and Associations with Language. Ear and hearing, 39(6), 1187-1198. https://doi.org/10.1097/AUD.0000000000000578

Childers, J. B., Parrish, R., Olson, C. V., Burch, C., Fung, G., \& McIntyre, K. P. (2016a). Early Verb Learning: How Do Children Learn How to Compare Events? Journal of Cognition and Development, 17(1), 41-66. https://doi.org/10.1080/15248372.2015.1042580

Childers, J. B., Parrish, R., Olson, C. V., Burch, C., Fung, G., \& McIntyre, K. P. (2016b). Early Verb Learning: How Do Children Learn How to Compare Events? Journal of Coqnition and Development, 17(1), 41-66. https://doi.org/10.1080/15248372.2015.1042580

Childers, J. B., \& Tomasello, M. (2001). The role of pronouns in young children's acquisition of the english transitive construction. Developmental Psychology, 37(6), 739. https://doi.org/10.1037/0012-1649.37.6. 739

Chilosi, A. M., Comparini, A., Scusa, M. F., Orazini, L., Forli, F., Cipriani, P., \& Berrettini, S. (2013). A longitudinal study of lexical and grammar development in deaf italian children provided with early cochlear implantation. Ear and Hearing, 34(3), e28-e37. https://doi.org/10. 1097/AUD.0b013e31827ad687

Cho, S., Holyoak, K. J., \& Cannon, T. D. (2007). Analogical reasoning in working memory: Resources shared among relational integration, interference resolution, and maintenance. Memory \&5 Cognition, 35(6), 1445-1455. https://doi.org/10.3758/BF03193614

Chuderski, A. (2014). The relational integration task explains fluid reasoning above and beyond other working memory tasks. Memory $\&$ Cognition, 42(3), 448-463. https://doi.org/10.3758/s13421-013-0366-x

Colquhoun, D. (2014). An investigation of the false discovery rate and the misinterpretation of p-values. Royal Society open science, 1(3), 140216. https://doi.org/10.1098/rsos.140216

Conway, C. M., Pisoni, D. B., Anaya, E. M., Karpicke, J., \& Henning, S. C. (2011). Implicit sequence learning in deaf children with cochlear implants. Developmental science, 14(1), 69-82. https:// doi.org/10. 1111/j.1467-7687.2010.00960.x

Conway, C. M., Pisoni, D. B., \& Kronenberger, W. G. (2009). The importance of sound for cognitive sequencing abilities: The auditory scaffolding 
hypothesis. Current directions in psycholoqical science, 18(5), 275279. https://doi.org/10.1111/j.1467-8721.2009.01651.x

Corps, R. E., Crossley, A., Gambi, C., \& Pickering, M. J. (2018). Early preparation during turn-taking: Listeners use content predictions to determine what to say but not when to say it. Cognition, 175, 77-95. https://doi.org/10.1016/j.cognition.2018.01.015

Cucis, P., Berger-Vachon, C., Gallego, S., \& Truy, E. (2018). Cochlear implant: On the number of channels. Modellinq, Measurement and Control C, 79(4), 179-184. https://doi.org/10.18280/mmc_c.790405

Cupples, L., Ching, T. Y., Button, L., Seeto, M., Zhang, V., Whitfield, J., Gunnourie, M., Martin, L., \& Marnane, V. (2018). Spoken language and everyday functioning in 5-year-old children using hearing aids or cochlear implants. International Journal of Audioloqu, 57(sup2), S55-S69. https://doi.org/10.1080/14992027.2017.1370140

Dauvier, B., Bailleux, C., \& Perret, P. (2014). The development of relational integration during childhood. Developmental Psychology, 50(6), 16871697. https://doi.org/10.1037/a0036655

Davidson, L. S., Geers, A. E., Hale, S., Sommers, M. M., Brenner, C., \& Spehar, B. (2019). Effects of Early Auditory Deprivation on Working Memory and Reasoning Abilities in Verbal and Visuospatial Domains for Pediatric Cochlear Implant Recipients: Ear and Hearing, 40(3), 517-528. https://doi.org/10.1097/AUD.0000000000000629

Dettman, S. J., Dowell, R. C., Choo, D., Arnott, W., Abrahams, Y., Davis, A., Dornan, D., Leigh, J., Constantinescu, G., Cowan, R., Et al. (2016). Long-term communication outcomes for children receiving cochlear implants younger than 12 months: A multicenter study. Otoloqy \& Neurotoloqy, 37(2), e82-e95. https://doi.org/10.1097/MAO. 0000000000000915

Diamond, A. (2013). Executive functions [PMID: 23020641]. Annual Review of Psycholoqy, 64(1), 135-168. https:// doi.org/10.1146/annurevpsych-113011-143750

Dillon, C. M., Burkholder, R. A., Cleary, M., \& Pisoni, D. B. (2004). Nonword repetition by children with cochlear implants. Journal of Speech, Lanquaqe, and Hearing Research. https://doi.org/10.1044/10924388(2004/082)

Dugbartey, A. T., Sanchez, P. N., Rosenbaum, J. G., Mahurin, R. K., Davis, J. M., \& Townes, B. D. (1999). WAIS-III Matrix Reasoning Test Performance in a Mixed Clinical Sample. The Clinical Neuropsycholoqist, 13(4), 396-404. https://doi.org/10.1076/1385-4046(199911)13:04;1Y;FT396

Edwards, L., Figueras, B., Mellanby, J., \& Langdon, D. (2011). Verbal and Spatial Analogical Reasoning in Deaf and Hearing Children: The Role of Grammar and Vocabulary. Journal of Deaf Studies and Deaf Education, 16(2), 189-197. https://doi.org/10.1093/deafed/enq051 
Eldblom, J., \& Sandberg, K. (2011). Svensk normering av trog-2 för åldrarna 6-8 år samt undersökning av sambandet mellan grammatisk språkförståelse och narrativförståelse. Retrieved September 6, 2017, from https://gupea.ub.gu.se/handle/2077/26897

Fortnum, H. M., Davis, A., Summerfield, A. Q., Marshall, D. H., Davis, A. C., Bamford, J. M., Yoshinaga-Itano, C., \& Hind, S. (2001). Prevalence of permanent childhood hearing impairment in the united kingdom and implications for universal neonatal hearing screening: Questionnaire based ascertainment studycommentary: Universal newborn hearing screening: Implications for coordinating and developing services for deaf and hearing impaired children. Bmj, 323(7312), 536. https:// doi.org/10.1136/bmj.323.7312.536

Geers, A. E., Moog, J. S., Biedenstein, J., Brenner, C., \& Hayes, H. (2009). Spoken language scores of children using cochlear implants compared to hearing age-mates at school entry. The Journal of Deaf Studies and Deaf Education, 14(3), 371-385. https://doi.org/10.1093/deafed/ enn046

Geers, A. E., \& Nicholas, J. G. (2013). Enduring advantages of early cochlear implantation for spoken language development. Journal of speech, lanquaqe, and hearinq research: JSLHR, 56(2), 643-655. https://doi. org/10.1044/1092-4388(2012/11-0347)

Geers, A. E., \& Sedey, A. L. (2011). Language and verbal reasoning skills in adolescents with 10 or more years of cochlear implant experience. Ear and hearinq, 32(1 Suppl), 39S. https://doi.org/10.1097/AUD. 0b013e3181fa41dc

Gelfand, S. A. (2009). Essentials of audiology. Thieme Medical Publishers, Inc., New York.

Gentner, D. (2016). Language as cognitive tool kit: How language supports relational thought. American Psychologist, 71(8), 650-657. https:// doi.org/10.1037/amp0000082

Gentner, D., \& Christie, S. (2010). Mutual bootstrapping between language and analogical processing. Lanquaqe and Cognition, 2(2), 261-283. https://doi.org/10.1515/langcog.2010.011

Gentner, D., \& Hoyos, C. (2017). Analogy and Abstraction. Topics in Cognitive Science, 9(3), 672-693. https://doi.org/10.1111/tops.12278

Gentner, D., Loewenstein, J., \& Hung, B. (2007). Comparison facilitates children's learning of names for parts. Journal of Cognition and Development, 8(3), 285-307.

Gentner, D., \& Namy, L. L. (1999). Comparison in the Development of Categories. Coqnitive Development, 14(4), 487-513. https://doi.org/10. 1016/S0885-2014(99)00016-7

Gentner, D., \& Namy, L. L. (2006). Analogical processes in language learning. Current Directions in Psychological Science, 15(6), 297-301. Re- 
trieved October 10, 2017, from http://journals.sagepub.com/doi/ abs/10.1111/j.1467-8721.2006.00456.x

Gentner, D., \& Smith, L. (2012). Analogical reasoning. Encyclopedia of human behavior, 130, 130. Retrieved September 6, 2017, from https://pdfs. semanticscholar.org/202b/bfc25fa83422d43c8439874857dc85c194d1. pdf

Gerken, L. (2006). Decisions, decisions: Infant language learning when multiple generalizations are possible. Coqnition, 98(3), B67-B74. https: //doi.org/10.1016/j.cognition.2005.03.003

Gerken, L. (2010). Infants use rational decision criteria for choosing among models of their input. Coqnition, 115(2), 362-366. https://doi.org/ 10.1016/j.cognition.2010.01.006

Gómez, R. L., \& Gerken, L. (2000). Infant artificial language learning and language acquisition. Trends in Cognitive Sciences, 4(5), 178-186. https://doi.org/1364-6613/00/\$

Gravel, J. S., \& O'Gara, J. (2003). Communication options for children with hearing loss. Mental retardation and developmental disabilities research reviews, 9(4), 243-251. https://doi.org/10.1002/mrdd.10087

Gust, H., Krumnack, U., Kühnberger, K.-U., \& Schwering, A. (2008). Analogical Reasoning: A Core of Cognition. KI, 22(1), 8-12. Retrieved September 6, 2017, from https:// www .researchgate.net/profile / Angela Schwering/publication/220634382 Analogical Reasoning_ A_Core_of_Cognition/links/56e33f7808ae65dd4cbac450.pdf

Hall, M. L., Hall, W. C., \& Caselli, N. K. (2019). Deaf children need language, not (just) speech [Number: 4 Reporter: FIRST LANGUAGE]. FIRST LANGUAGE, 39(4), 367-395. https:// doi.org/10.1177/ 0142723719834102

Hammill, D. D., Mather, N., \& Rhia, R. (2013). Itpa-3: Illinois test of psycholinguistic abilities. manual (B. Holmgren, Trans.). Psykologiförlaget.

Hannemann, R., Obleser, J., \& Eulitz, C. (2007). Top-down knowledge supports the retrieval of lexical information from degraded speech. Brain research, 1153, 134-143. https://doi.org/10.1016/j.brainres.2007.03. 069

Hansson, K., Ibertsson, T., Asker-Árnason, L., \& Sahlén, B. (2018). Language impairment in children with ci: An investigation of swedish. Lingua, 213, 63-77. https://doi.org/10.1016/j.lingua.2018.07.001

Hess, C., Zettler-Greeley, C., Godar, S. P., Ellis-Weismer, S., \& Litovsky, R. Y. (2014). The effect of differential listening experience on the development of expressive and receptive language in children with bilateral cochlear implants. Ear and hearing, 35(4), 387. https://doi. org/10.1097/AUD.0000000000000023

Holck, P., Nettelbladt, U., \& Sandberg, A. D. (2009). Children with cerebral palsy, spina bifida and pragmatic language impairment: Differences 
and similarities in pragmatic ability. Research in developmental disabilities, 30(5), 942-951. https://doi.org/10.1016/j.ridd.2009.01.008

Holt, R. F., \& Kirk, K. I. (2005). Speech and language development in cognitively delayed children with cochlear implants. Ear and hearing, 26(2), 132-148. https://doi.org/0196/0202/05/2602-0132/0

Ibertsson, T., Hansson, K., Mäki-Torkko, E., Willstedt-Svensson, U., \& Sahlén, B. (2009). Deaf teenagers with cochlear implants in conversation with hearing peers. International Journal of Lanquaqe $8 \mathrm{Com}$ munication Disorders, 44(3), 319-337. https://doi.org/10.1080/ 13682820802052067

Jeanes, R. C., Nienhuys, T. G., \& Rickards, F. W. (2000). The pragmatic skills of profoundly deaf children. Journal of Deaf Studies and Deaf Education, 5(3), 237-247. https://doi.org/10.1093/deafed/5.3.237

Kane, M. J., Hambrick, D. Z., Tuholski, S. W., Wilhelm, O., Payne, T. W., \& Engle, R. W. (2004). The Generality of Working Memory Capacity: A Latent-Variable Approach to Verbal and Visuospatial Memory Span and Reasoning. Journal of Experimental Psycholoqy: General, 133(2), 189-217. https://doi.org/10.1037/0096-3445.133.2.189

Karltorp, E., Eklöf, M., Östlund, E., Asp, F., Tideholm, B., \& Löfkvist, U. (2020). Cochlear implants before 9 months of age led to more natural spoken language development without increased surgical risks. Acta Paediatrica, 109(2), 332-341. https://doi.org/10.1111/apa.14954

Kenett, Y. N., Wechsler-Kashi, D., Kenett, D. Y., Schwartz, R. G., BenJacob, E., \& Faust, M. (2013). Semantic organization in children with cochlear implants: Computational analysis of verbal fluency. Frontiers in Psychology, 4. https://doi.org/10.3389/fpsyg.2013.00543

Ketelaar, L., Rieffe, C., Wiefferink, C. H., \& Frijns, J. H. (2012). Does hearing lead to understanding? theory of mind in toddlers and preschoolers with cochlear implants. Journal of Pediatric Psychology, 37(9), 10411050. https://doi.org/10.1093/jpepsy/jss086

Klauer, K. J., \& Phye, G. D. (2008). Inductive Reasoning: A Training Approach. Review of Educational Research, 78(1), 85-123. https://doi. org/10.3102/0034654307313402

Klauer, K. J. (1989a). Denktraining für Kinder I [Training to reason for children I]. Göttingen, Germany, Hogrefe.

Klauer, K. J. (1989b). Teaching for analogical transfer as a means of improving problem-solving, thinking and learning. Instructional Science, 18(3), 179-192. https://doi.org/10.1007/BF00053358

Klauer, K. J. (1996). Teaching inductive reasoning: Some theory and three experimental studies. Learning and Instruction, 6(1), 37-57. https: //doi.org/10.1016/0959-4752(95)00015-1

Korver, A. M. H., Smith, R. J. H., Van Camp, G., Schleiss, M. R., BitnerGlindzicz, M. A. K., Lustig, L. R., Usami, S.-i., \& Boudewyns, A. N. 
(2017). Congenital hearing loss. Nature Reviews Disease Primers, 3(1), 16094. https://doi.org/10.1038/nrdp.2016.94

Kral, A., Kronenberger, W. G., Pisoni, D. B., \& O’Donoghue, G. M. (2016). Neurocognitive factors in sensory restoration of early deafness: A connectome model. The Lancet Neurology, 15(6), 610-621. https://doi. org/10.1016/S1474-4422(16)00034-X

Kronenberger, W. G. (2019). Executive functioning and language development in children with cochlear implants. Cochlear implants international, 20(Suppl 1), 2.

Kronenberger, W. G., Colson, B. G., Henning, S. C., \& Pisoni, D. B. (2014). Executive functioning and speech-language skills following long-term use of cochlear implants. Journal of deaf studies and deaf education, 19(4), 456-470. https://doi.org/10.1093/deafed/enu011

Kronenberger, W. G., \& Pisoni, D. B. (2019). Assessing higher order language processing in long-term cochlear implant users. American journal of speech-language pathology, 28(4), 1537-1553.

Krzemien, M., Jemel, B., \& Maillart, C. (2017). Analogical reasoning in children with specific language impairment: Evidence from a scene analogy task. Clinical Linquistics \& Phonetics, 31(7), 573-588. https: //doi.org/10.1080/02699206.2017.1302509

Kurdek, L. A., \& Sinclair, R. J. (2000). Psychological, family, and peer predictors of academic outcomes in first-through fifth-grade children. Journal of Educational Psychology, 92(3), 449. https://doi.org/10.1037/ 0022-0663.92.3.449

Lenhard, A., \& Lenhard, W. (2011). Computerbasierte Intelligenzförderung mit dem Denkspielen mit Elfe und Mathis - Vorstellung und Evaluation eines Computerprogramms für Vor- und Grundschüler. Empirische Sonderpädagogik, 2, 105-120.

Lenhard, A., Lenhard, W., \& Klauer, K. J. (2011). Denkspiele mit Elfe und Mathis - Förderung des logischen Denkvermögens für das Vor- und Grundschulalter. Göttingen, Germany, Hogrefe.

Leroy, S., Maillart, C., \& Parisse, C. (2014). Analogical mapping across modalities in children with specific language impairment (SLI). Research in developmental disabilities, 35(9), 2158-2171. Retrieved September 6, 2017, from http://www.sciencedirect.com/science/article/pii/ S0891422214002054

Leroy, S., Parisse, C., \& Maillart, C. (2012). Analogical reasoning in children with specific language impairment. Clinical Linquistics $\&$ Phonetics, 26(4), 380-396. https://doi.org/10.3109/02699206.2011.641059

Levinson, S. C. (2016). Turn-taking in Human Communication - Origins and Implications for Language Processing. Trends in Cognitive Sciences, 20(1), 6-14. https://doi.org/10.1016/j.tics.2015.10.010

Liu, M., Wu, L., Wu, W., Li, G., Cai, T., \& Liu, J. (2018). The relationships among verbal ability, executive function, and theory of mind in young 
children with cochlear implants. International journal of audiology, 57(12), 881-888. https://doi.org/10.1080/14992027.2018.1498982

Loizou, P. C. (2006). Speech processing in vocoder-centric cochlear implants. In Cochlear and brainstem implants (pp. 109-143). Karger Publishers.

Loukusa, S., Leinonen, E., \& Ryder, N. (2007). Development of pragmatic language comprehension in Finnish-speaking children. First Language, 27(3), 279-296. https://doi.org/10.1177/0142723707076568

Lund, E. (2016). Vocabulary Knowledge of Children With Cochlear Implants: A Meta-Analysis. Journal of Deaf Studies and Deaf Education, 21(2), 107-121. https://doi.org/10.1093/deafed/env060

Marcus, G. F. (1999). Rule Learning by Seven-Month-Old Infants. Science, 283(5398), 77-80. https://doi.org/10.1126/science.283.5398.77

Marx, E. (2006). Profitiert das kindliche sprachsystem von anderen kognitiven entwicklungsbereichen? Pilotstudie zum zusammenhang von spracherwerb und induktivem denken. Zeitschrift fur Entwicklunqspsycholoqie und Padaqoqische Psychologie, 38(3), 139-145. https://doi.org/10.1026/0049-8637.38.3.139

Marx, E., Keller, K., \& Beuing, R. (2010). Die Erzieherin als Trainerin. Effekte kombinierter Denk- und Sprachförderung in Kindertagesstätten. Psycholoqie in Erziehunq und Unterricht, 57(1), 41-51. https: //doi.org/10.2378/peu2011.art03d

Masterson, J. J., Evans, L. H., \& Aloia, M. (1993). Verbal Analogical Reasoning in Children With Language-Learning Disabilities. Journal of Speech, Lanquaqe, and Hearing Research, 36(1), 76-82. https://doi. org/10.1044/jshr.3601.76

Matthews, D., Biney, H., \& Abbot-Smith, K. (2018). Individual Differences in Children's Pragmatic Ability: A Review of Associations with Formal Language, Social Cognition, and Executive Functions. Lanquaqe Learning and Development, 14(3), 186-223. https://doi.org/10.1080/ 15475441.2018.1455584

May-Mederake, B. (2012). Early intervention and assessment of speech and language development in young children with cochlear implants. International Journal of Pediatric Otorhinolaryngology, 76(7), 939-946. https://doi.org/10.1016/j.ijporl.2012.02.051

Meinzen-Derr, J., Wiley, S., Grether, S., \& Choo, D. I. (2011). Children with cochlear implants and developmental disabilities: A language skills study with developmentally matched hearing peers. Research in Developmental Disabilities, 32(2), 757-767. https://doi.org/10.1016/j. ridd.2010.11.004

Mitchell, R. E., \& Karchmer, M. A. (2004). Chasing the mythical ten percent: Parental hearing status of deaf and hard of hearing students in the United States. Sign Language Studies, 4(2), 138-163.

Most, T., Shina-August, E., \& Meilijson, S. (2010). Pragmatic Abilities of Children With Hearing Loss Using Cochlear Implants or Hearing Aids 
Compared to Hearing Children. Journal of Deaf Studies and Deaf Education, 15(4), 422-437. https://doi.org/10.1093/deafed/enq032

Nittrouer, S., Caldwell-Tarr, A., Low, K. E., \& Lowenstein, J. H. (2017). Verbal working memory in children with cochlear implants. Journal of Speech, Lanquaqe, and Hearing Research, 60(11), 3342-3364. https: //doi.org/10.1044/2017_JSLHR-H-16-0474

Paatsch, L. E., \& Toe, D. M. (2014). A comparison of pragmatic abilities of children who are deaf or hard of hearing and their hearing peers. Journal of deaf studies and deaf education, 19(1), 1-19. https://doi. org/10.1093/deafed/ent030

Pearson Education. (2008a). CELF \& sample reports. https : / / www pearsonclinical.co.uk/Psychology/ChildCognitionNeuropsychology $\%$ 20andLanguage / ChildLanguage / ClinicalEvaluationofLanguage \% 20Fundamentals - FourthEditionUK(CELF - 4UK )/Resources / CELF4Sample\%20Report.pdf

Pearson Education. (2008b). CELF \& technical report. http : / / images pearsonassessments.com/images/tmrs/tmrs_rg/CELF_4_Tech_ Report.pdf

Pixner, S., Leyrer, M., \& Moeller, K. (2014). Number processing and arithmetic skills in children with cochlear implants. Frontiers in psychology, 5, 1479. https://doi.org/10.3389/fpsyg.2014.01479

R Core Team. (2016). R: A language and environment for statistical computinq. Vienna, Austria, R Foundation for Statistical Computing. https: //www.R-project.org/

Raven, J. C., \& Court, J. (1938). Raven's progressive matrices. Western Psychological Services Los Angeles, CA.

Rönnberg, J., Lunner, T., Zekveld, A., Sörqvist, P., Danielsson, H., Lyxell, B., Dahlström, Ö., Signoret, C., Stenfelt, S., Pichora-Fuller, M. K., \& Rudner, M. (2013). The Ease of Language Understanding (ELU) model: Theoretical, empirical, and clinical advances. Frontiers in Systems Neuroscience, 7. https://doi.org/10.3389/fnsys.2013.00031

Roth-van der Werf, T., Resing, W. C. M., \& Slenders, A. (2002). Task Similarity and Transfer of an Inductive Reasoning Training. Contemporary Educational Psychology, 325, 296-325. https://doi.org/10.1006/ceps. 2001.1096

Ruben, R. J. (1997). A time frame of critical/sensitive periods of language development. Acta oto-larynqologica, 117(2), 202-205. https://doi. org/10.3109/00016489709117769

Sandhofer, C. (2001). Structure in Parents' Input: Effects of Categorization versus Comparison. In Proceedings of the 25th Annual Boston University Conference on Language Development, Vols. 1-2 (pp. 657-667). Somerville, MA, US, Cascadilla Press.

Semel, E. M., Wiig, E. H., \& Secord, W. (2004). Celf 4: Clinical evaluation of language fundamentals 4 screening test. Pearson, PsyhCorp. 
Sperber, D., \& Wilson, D. (2004). Relevance theory. Handbook of Pragmatics. Oxford: Blackwell, 607-632.

Stevenson, C. E., Hickendorff, M., Resing, W. C., Heiser, W. J., \& de Boeck, P. A. (2013). Explanatory item response modeling of children's change on a dynamic test of analogical reasoning. Intelligence, 41(3), 157168. https://doi.org/10.1016/j.intell.2013.01.003

Sundqvist, A., Lyxell, B., Jönsson, R., \& Heimann, M. (2014). Understanding minds: Early cochlear implantation and the development of theory of mind in children with profound hearing impairment. International Journal of Pediatric Otorhinolaryngology, 78(3), 538-544. https:// doi.org/10.1016/j.ijporl.2013.12.039

Sundström, S., Löfkvist, U., Lyxell, B., \& Samuelsson, C. (2018). Prosodic and segmental aspects of nonword repetition in 4-to 6-year-old children who are deaf and hard of hearing compared to controls with normal hearing. Clinical Linquistics \&6 Phonetics, 32(10), 950-971. https: //doi.org/10.1080/02699206.2018.1469671

Süß, H.-M., Oberauer, K., Wittmann, W. W., Wilhelm, O., \& Schulze, R. (2002). Working-memory capacity explains reasoning ability-and a little bit more. Intelliqence, 30(3), 261-288. https://doi.org/10.1016/ S0160-2896(01)00100-3

Thagard, E. K., Hilsmier, A. S., \& Easterbrooks, S. R. (2011). Pragmatic language in deaf and hard of hearing students: Correlation with success in general education. American annals of the deaf, 155(5), 526-534. https://doi.org/10.1353/aad.2011.0008

Toe, D. M., \& Paatsch, L. E. (2013). The conversational skills of school-aged children with cochlear implants. Cochlear Implants International, 14(2), 67-79. https://doi.org/10.1179/1754762812Y.0000000002

Tomasello, M. (2000). First steps toward a usage-based theory of language acquisition. Cognitive linquistics, 11(1/2), 61-82. Retrieved October 13, 2017, from http://www.let.rug.nl/ nerbonne/teach/languagelearning/papers/tomasello_2000.pdf

Tomasello, M. (2009). The usage-based theory of language acquisition. In The cambridge handbook of child language (pp. 69-87). Cambridge Univ. Press.

Turkstra, L. S., McDonald, S., \& Kaufmann, P. M. (1996). Assessment of pragmatic communication skills in adolescents after traumatic brain injury. Brain injury, 10(5), 329-346.

van der Schuit, M., Segers, E., van Balkom, H., \& Verhoeven, L. (2011). How cognitive factors affect language development in children with intellectual disabilities. Research in Developmental Disabilities, 32(5), 1884-1894. https://doi.org/10.1016/j.ridd.2011.03.015

von Koss Torkildsen, J., Arciuli, J., Haukedal, C. L., \& Wie, O. B. (2018). Does a lack of auditory experience affect sequential learning? Cognition, 170, 123-129. https://doi.org/10.1016/j.cognition.2017.09.017 
von Mentzer, C. N., Lyxell, B., Sahlén, B., Wass, M., Lindgren, M., Ors, M., Kallioinen, P., \& Uhlén, I. (2013). Computer-assisted training of phoneme-grapheme correspondence for children who are deaf and hard of hearing: Effects on phonological processing skills. International Journal of Pediatric Otorhinolarynqology, rr7(12), 2049-2057. https://doi.org/10.1016/j.ijporl.2013.10.007

Wass, M., Ibertsson, T., Lyxell, B., Sahlen, B., Hällgren, M., Larsby, B., \& Mäki-Torkko, E. (2008). Cognitive and linguistic skills in swedish children with cochlear implants-measures of accuracy and latency as indicators of development. Scandinavian Journal of Psychology, 49(6), 559-576. https://doi.org/10.1111/j.1467-9450.2008.00680.x

Wass, M., Löfkvist, U., Anmyr, L., Karltorp, E., Östlund, E., \& Lyxell, B. (2019). Correlates of orthographic learning in swedish children with cochlear implants. Frontiers in Psychology, 10, 143. https://doi.org/ 10.3389/fpsyg.2019.00143

Wechsler, D., \& Naglieri, J. A. (2007). WNV: Svensk version : Manual (M. Garsell, Trans.) [Google-Books-ID: igjWjwEACAAJ]. Harcourt Assessment.

Werfel, K. L., \& Hendricks, A. E. (2016). The Relation Between Child Versus Parent Report of Chronic Fatigue and Language/Literacy Skills in School-Age Children with Cochlear Implants. https://doi.org/info: doi/10.1097/AUD.0000000000000242

Willstedt-Svensson, U., Löfqvist, A., Almqvist, B., \& Sahlén, B. (2004). Is age at implant the only factor that counts? The influence of working memory on lexical and grammatical development in children with cochlear implants. International Journal of Audiology, 43(9), 506515. https://doi.org/10.1080/14992020400050065

Zeng, F.-G. (2004). Trends in cochlear implants. Trends in amplification, 8(1), 1-34. https://doi.org/10.1177/108471380400800102 



\section{Papers}

The papers associated with this thesis have been removed for copyright reasons. For more details about these see:

http://urn.kb.se/resolve?urn=urn:nbn:se:liu:diva-168810 


\section{Studies from the Swedish Institute for Disability Research}

1. Varieties of reading disability

Stefan Gustafson

ISBN 91-7219-867-2, 2000

2. Cognitive functions in drivers with brain injury - anticipation and adaptation Anna Lundqvist

ISBN 91-7219-967-9, 2001

3. Cognitive deafness

Ulf Andersson

ISBN 91-7373-029-7, 2001

4. Att lära sig leva med förvärvad hörselnedsättning sett ur par-perspektiv

Carin Fredriksson

ISBN 91-7373-105-6, 2001

5. Signs, Symptoms, and Disability Related to the Musculo-Skeletal System Gunnar Lundberg ISBN 91-7373-160-9, 2002

6. Participation - Ideology and Everyday Life

Anette Kjellberg

ISBN 91-7373-371-7, 2002

7. Föräldrar med funktionshinder - om barn, föräldraskap och familjeliv

Marie Gustavsson Holmström

ISBN 91-7203-500-5, 2002

8. Active wheelchair use in daily life

Kersti Samuelsson

ISBN 91-7373-196-X, 2002

9. Två kön eller inget alls. Politiska intentioner och vardagslivets realiteter i den arbetslivsinriktade rehabiliteringen

Marie Jansson

ISBN 91-7373-568-X, 2003 
10. Audiological and cognitive long-term sequelae from closed head injury Per-Olof Bergemalm

ISBN 91-7668-384-2, 2004

11. Att vara i särklass - om delaktighet och utanförskap i gymnasiesärskolan Martin Molin

ISBN 91-85295-46-9, 2004

12. Rättvis idrottsundervisning för elever med rörelsehinder - dilemma kring omfördelning och erkännande

Kajsa Jerlinder

Licentiate Degree, 2005

13. Hearing impairment and deafness. Genetic and environmental factors interactions - consequences. A clinical audiological approach

Per-Inge Carlsson

ISBN 91-7668-426-1, 2005

14. Hearing and cognition in speech comprehension. Methods and applications Mathias Hällgren

ISBN 91-85297-93-3, 2005

15. Living with deteriorating and hereditary disease: experiences over ten years of persons with muscular dystrophy and their next of kin

Katrin Boström

ISBN 91-7668-427-x, 2005

16. Disease and disability in early rheumatoid arthritis

Ingrid Thyberg

ISBN 91-85299-16-2, 2005

17. "Varför får jag icke följa med dit fram?" Medborgarskapet och den offentliga debatten om dövstumma och blinda 1860-1914

Staffan Bengtsson

ISBN 91-85457-06-X, 2005

18. Modalities of Mind. Modality-specific and nonmodality-specific aspects of working memory for sign and speech

Mary Rudner

ISBN 91-85457-10-8, 2005 
19. Facing the Illusion Piece by Piece. Face recognition for persons with learning disability

Henrik Danielsson

ISBN 91-85497-09-6, 2006

20. Vuxna med förvärvad traumatisk hjärnskada - omställningsprocesser och konsekvenser i vardagslivet. En studie av femton personers upplevelser och erfarenheter av att leva med förvärvad traumatisk hjärnskada

Thomas Strandberg

ISBN 91-7668-498-9, 2006

21. Nycklar till kommunikation. Kommunikation mellan vuxna personer med grav förvärvad hjärnskada och personernas närstående, anhöriga och personal

Pia Käcker

ISBN 978-91-85715-88-6, 2007

22. "Aspergern, det är jag”. En intervjustudie om att leva med Asperger syndrom

Gunvor Larsson Abbad

ISBN 978-91-85831-43-2, 2007

23. Sounds of silence - Phonological awareness and written language in children with and without speech

Janna Ferreira

ISBN 978-91-85895-74-8, 2007

24. Postponed Plans: Prospective Memory and Intellectual Disability

Anna Levén

ISBN 978-91-85895-57-1, 2007

25. Consequences of brain tumours from the perspective of the patients and of their next of kin

Tanja Edvardsson

ISBN 978-91-7668-572-3, 2008

26. Impact on participation and service for persons with deafblindness

Kerstin Möller

ISBN 978-91-7668-595-2, 2008

27. Approaches to Audiological Rehabilitation with Hearing Aids: studies on prefitting strategies and assessment of outcomes

Marie Öberg

ISBN 978-91-7393-828-0, 2008 
28. Social Interaction and Participation in Activities of Everyday Life Among Persons with Schizophrenia

Maria Yilmaz

Licentiate Degree, 2009

29. Focus on Chronic Disease through Different Lenses of Expertise

Towards Implementation of Patient-Focused

Decision Support Preventing Disability:

The example of Early Rheumatoid Arthritis

Örjan Dahlström

ISBN 978-91-7393-613-2, 2009

30. Children with Cochlear Implants: Cognition and Reading Ability

Malin Wass

ISBN: 978-91-7393-487-9, 2009

31. Restricted participation:

Unaccompanied children in interpreter-mediated asylum hearings in Sweden

Olga Keselman

ISBN: 978-91-7393-499-2, 2009

32. Deaf people and labour market in Sweden.

Education - Employment - Economy

Emelie Rydberg

ISBN: 978-91-7668-725-3, 2010

33. Social rättvisa i inkluderande idrottsundervisning

för elever med rörelsehinder - en utopi?

Kajsa Jerlinder

ISBN: 978-91-7668-726-0, 2010

34. Erfarenheter av rehabiliteringsprocessen mot ett arbetsliv

- brukarens och de professionellas perspektiv

Helene Hillborg

ISBN: 978-91-7668-741-3, 2010

35. Knowing me, knowing you - Mentalization abilities of children who use augmentative and alternative communication

Annette Sundqvist

ISBN: 978-91-7393-316-2, 2010 
36. Lärare, socialsekreterare och barn som far illa - om sociala representationer och interprofessionell samverkan

Per Germundsson

ISBN: 978-91-7668-787-1, 2011

37. Fats in Mind

Effects of Omega-3 Fatty Acids on Cognition and Behaviour in Childhood

Ulrika Birberg Thornberg

ISBN: 978-91-7393-164-9, 2011

38. "Jobbet är kommunikation"

Om användning av arbetshjälpmedel för personer med hörselnedsättning

Sif Bjarnason

Licentiate Degree. ISBN: 978-91-7668-835-9, 2011

39. Applying the ICF-CY to identify everyday life situations of children and youth with disabilities

Margareta Adolfsson

ISBN: 978-91-628-8342-3, 2011

40. Tinnitus - an acceptance-based approach

Vendela Zetterqvist

ISBN: 978-91-7393-040-6, 2011

41. Applicability of the ICF-CY to describe functioning and environment of children with disabilities

Nina Klang

ISBN: 978-91-7668-864-9, 2012

42. Bringing more to participation

Participation in school activities of persons with Disability within the framework of the International Classification of Functioning, Disability and Health for Children and Youth (ICF-CY)

Gregor Maxwell

ISBN: 978-91-628-8484-0, 2012

43. From Eye to Us.

Prerequisites for and levels of participation in mainstream school of persons with Autism Spectrum Conditions

Marita Falkmer

ISBN: 978-91-637-2091-8, 2013 
44. Otosclerosis, clinical long-term perspectives

Ylva Dahlin-Redfors

ISBN 978-91-628-8617-2, 2013

45. Tinnitus in Context - A Contemporary Contextual Behavioral Approach Hugo Hesser

ISBN 978-91-7519-701-2, 2013

46. Hearing and middle ear status in children and young adults with cleft palate Traci Flynn

ISBN 978-91-628-8645-5, 2013

47. Utrymme för deltagande, beslutsprocesser i möten mellan patienter med ospecifika ländryggsbesvär och sjukgymnaster i primär vård

Iréne Josephson

ISBN 42-978-91-85835-41-6, 2013

48. "Man vill ju klara sig själv" Studievardagen för studenter med Asperger syndrom i högre studier

Ann Simmeborn Fleischer

ISBN 978-91-628-8681-3, 2013

49. Cognitive erosion and its implications in Alzheimer's disease

Selina Mårdh

ISBN 978-91-7519-621-1, 2013

50. Hörselscreening av en population med utvecklingsstörning

Utvärdering av psykoakustisk testmetod och av OAE-registrering som komplementär metod

Eva Andersson

Licentiate Degree. ISBN 978-91-7519-616-9, 2013

51. Skolformens komplexitet - elevers erfarenheter av skolvardag och tillhörighet i gymnasiesärskolan

Therése Mineur

ISBN 978-91-7668-951-6, 2013

52. Evaluating the process of change:

Studies on patient journey, hearing disability acceptance and stages-of-change

Vinaya Kumar Channapatna Manchaiah

ISBN 978-91-7519-534-6, 2013 
53. Cognition in hearing aid users: Memory for everyday speech

Hoi Ning (Elaine) $\mathrm{Ng}$

ISBN 978-91-7519-494-3, 2013

54. Representing sounds and spellings Phonological decline and compensatory working memory in acquired hearing impairment

Elisabet Classon

ISBN 978-91-7519-500-1, 2013

55. Assessment of participation in people with a mild intellectual disability

Patrik Arvidsson

ISBN 978-91-7668-974-5, 2013

56. Barnperspektiv i barnavårdsutredningar - med barns hälsa och barns

upplevelser i fokus

Elin Hultman

ISBN 978-91-7519-457-8, 2013

57. Internet Interventions for Hearing Loss

Examining rehabilitation Self-report measures and Internet use in hearing-aid users

Elisabet Sundewall Thorén

ISBN 978-91-7519-423-3, 2014

58. Exploring Cognitive Spare Capacity: Executive Processing of Degraded Speech Sushmit Mishra

ISBN 978-91-7519-386-1, 2014

59. Supported employment i en svensk kontext - förutsättningar när personer med funktionsnedsättning når, får och behåller ett arbete

Johanna Gustafsson

ISBN 978-91-7529-012-6, 2014

60. Effects of Specific Cochlear Pathologies on the Auditory Functions:

Modelling, Simulations and Clinical Implications

Amin Saremi

ISBN 978-91-7519-365-6, 2014 
61. Children with profound intellectual and multiple disabilities and their participation in family activities

Anna Karin Axelsson

ISBN 978-91-85835-48-5, 2014

62. Lexical and Semantic Development in Children With Cochlear Implants

Ulrika Löfkvist

ISBN 978-91-7549-546-0, 2014

63. Rethinking sound. Computer-assisted reading intervention with a phonics approach for deaf and hard of hearing children using cochlear implants or hearing aids

Cecilia Nakeva von Mentzer

ISBN 978-91-7519-270-3, 2014

64. Assessing cognitive spare capacity as a measure of listening effort using the Auditory Inference Span Test

Niklas Rönnberg

ISBN 978-91-7519-267-3, 2014

65. Employees with Aided Hearing Impairment: An Interdisciplinary Perspective Håkan Hua

ISBN 978-91-7519-240-6, 2014

66. Prosthetic and Orthotic Services in Developing Countries

Lina Magnusson

ISBN 978-91-85835-55-3, 2014

67. Dealing with digits - Arithmetic, memory and phonology in deaf signers Josefine Andin

ISBN: 978-91-7519-235-2, 2014

68. Time is of the essence in speech recognition: Get it fast or think about it Shahram Moradi

ISBN: 978-91-7519-188-1, 2014

69. Effects of hearing loss on traffic safety and mobility

Birgitta Thorslund

ISBN: 978-91-7519-178-2, 2014 
70. Aspekter på lärande vid dövblindhet - möjligheter och begränsningar för personer med Alström syndrom

Berit Rönnåsen

Licentiate Degree. ISBN: 978-91-7529-068-3, 2015

71. Memory and communication in typically developing infants and children with Autism Spectrum Disorder: Behavioral and electrophysiological indices

Emelie Nordqvist

ISBN: 978-91-7519-078-5, 2015

72. Cognitive capacities and composite cognitive skills in individuals with

Usher syndrome type 1 and 2

Cecilia Henricson

ISBN: 978-91-7685-999-5, 2015

73. Functioning and Disability in Adults with Hearing Loss

Preparatory studies in the ICF Core Sets for Hearing Loss project

Sarah Granberg

ISBN: 978-91-7529-086-7, 2015

74. Speech recognition and memory processes in native and non-native language perception

Lisa Kilman

ISBN: 978-91-7685-972-8, 2015

75. To include or not to include: Teachers' social representations of inclusion of students with Asperger diagnosis

Ann-Charlotte Linton

ISBN: 978-91-7685-956-8, 2015

76. Health and People with Usher syndrome

Moa Wahlqvist

ISBN: 978-91-7529-098-0, 2015

77. Children with mild intellectual disability and their families - needs for support, service utilisation and experiences of support

Lena Olsson

ISBN: 978-91-85835-66-9, 2016 
78. Deafblindness

Theory-of-mind, cognitive functioning and social network in Alström syndrome

Hans-Erik Frölander

ISBN: 978-91-7529-132-1, 2016

79. Signs for Developing Reading

Sign Language and Reading Development in Deaf and Hard-of-Hearing Children

Emil Holmer

ISBN: 978-91-7685-767-0, 2016

80. Speech masking speech in everyday communication

The role of inhibitory control and working memory capacity

Victoria Stenbäck

ISBN: 978-7685-604-8, 2017

81. Neural and Cognitive Effects of Hearing Loss on Speech Processing

Eline Borch Petersen

ISBN: 978-91-7685-640-6, 2017

82. A biopsychosocial approach to functioning, oral health and specialist dental health care in children with disabilities - Swedish and international perspectives

Johanna Norderyd

ISBN: 978-91-85835-81-2, 2017

83. Samverkansprojekt, och sen då? - en uppföljande studie av samverkansprocessen kring barn och unga som far illa eller riskerar att fara illa

Ulrika Englund

ISBN: 978-91-7529-194-9, 2017

84. Aural rehabilitation programs for hearing aid users

Evaluating and clinically applying educational programs, supported via telephone and/or the internet and professionally guided by an audiologist

Milijana Malmberg

ISBN: 978-91-629-0187-5, 2017

85. Tolkning vid förmedlade samtal via Bildtelefoni.net

- interaktion och gemensamt meningsskapande

Camilla Warnicke

ISBN: 978-91-7529-197-0, 2017 
86. Vardagslivets aktiviteter. Handlingen som terapeutiskt redskap för personer med svårare psykiska funktionshinder - Analys av arbetsterapeuters berättelser med utgångspunkt i G H Meads teori om social handling

Marianne Boström

ISBN: 978-91-7529-206-9, 2017

87. Creative disability classification systems: The case of Greece, 1990-2015

Antonia Pavli

ISBN: 978-91-7529-204-5, 2017

88. Ej utgiven

89. Perception of disturbing sounds

Investigations of people with hearing loss and normal hearing

Åsa Skagerstrand

ISBN: 978-91-7529-229-8, 2018

90. Peer Interaction in Preschool: Necessary, but not Sufficient The Influence of Social Interaction on the Link between Behaviour Difficulties and Engagement among Children with and without Need of Special Support Madeleine Sjöman

ISBN: 978-91-88339-13-3, 2018

91. Prosodic and Phonological Ability in Children with Developmental Language Disorder and Children with Hearing Impairment In the context of Word and Nonword Repetition

Simon Sundström

ISBN: 978-91-7685-321-4, 2018

92. From detection to intervention

Psychological aspects of online hearing rehabilitation

Peter Molander

ISBN: 978-91-7685-226-2, 2018 
93. Participation in and outside school

Self-ratings by Swedish adolescents with and without impairments and long-term health conditions

Frida Lygnegård

ISBN: 978-91-85835-92-8, 2018

94. Återgång $\mathrm{i}$ arbete efter förvärvad hjärnskada

- livskvalitet, möjligheter och hinder

Marie Matérne

ISBN: 978-91-7529-267-0, 2018

95. Climbing up the hearing rehabilitation ladder

Elisabeth Ingo

ISBN: 978-91-7519-011-2, 2019

96. Situationen på den svenska arbetsmarknaden för personer med funktionsnedsättning

En sekundäranalys om sysselsättning, yrkesnivå, diskriminering, stöd och anpassning för personer med olika typer av funktionsnedsättning

Tomas Boman

ISBN: 978-91-7529-302-8, 2019

97. Different is cool!

Self-efficacy and participation of students with and without disabilities in school-based Physical Education

Karin Bertills

ISBN: 978-91-88339-26-3, 2019

98. Fonologisk utveckling hos barn med otitbenägenhet

En longitudinell studie i åldrarna 3;6 till 5;6 år

Helena Stålnacke

Licentiate Degree. ISBN: 978-91-7529-321-9, 2020

99. Life Strategies, Work and Health in People with Usher Syndrome Mattias Ehn

ISBN: 978-91-7529-322-6, 2020 
100. Time to Plan:

How to support everyday planning in adolescents with intellectual disability Lisa Palmqvist

ISBN: 978-91-7929-869-2, 2020 


\section{FACULTY OF ARTS AND SCIENCES}

Linköping Studies in Arts and Sciences, Dissertation No. 795, 2020 Studies from the Swedish Institute for Disability Research No. 101 Department of Behavioural Sciences and Learning

Linköping University

SE-581 83 Linköping, Sweden

www.liu.se

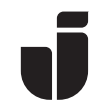

